\title{
A Dynamical and Statistical Characterization of U.S. Extreme Precipitation Events and Their Associated Large-Scale Meteorological Patterns ${ }^{\mathscr{D}}$
}

\author{
Siyu ZhaO, Yi Deng, AND Robert X. BLACK \\ School of Earth and Atmospheric Sciences, Georgia Institute of Technology, Atlanta, Georgia
}

(Manuscript received 20 December 2015, in final form 26 October 2016)

\begin{abstract}
Regional patterns of extreme precipitation events occurring over the continental United States are identified via hierarchical cluster analysis of observed daily precipitation for the period 1950-2005. Six canonical extreme precipitation patterns (EPPs) are isolated for the boreal warm season and five for the cool season. The large-scale meteorological pattern (LMP) inducing each EPP is identified and used to create a "base function" for evaluating a climate model's potential for accurately representing the different patterns of precipitation extremes. A parallel analysis of the Community Climate System Model, version 4 (CCSM4), reveals that the CCSM4 successfully captures the main U.S. EPPs for both the warm and cool seasons, albeit with varying degrees of accuracy. The model's skill in simulating each EPP tends to be positively correlated with its capability in representing the associated LMP. Model bias in the occurrence frequency of a governing LMP is directly related to the frequency bias in the corresponding EPP. In addition, however, discrepancies are found between the CCSM4's representation of LMPs and EPPs over regions such as the western United States and Midwest, where topographic precipitation influences and organized convection are prominent, respectively. In these cases, the model representation of finer-scale physical processes appears to be at least equally important compared to the LMPs in driving the occurrence of extreme precipitation.
\end{abstract}

\section{Introduction}

Extreme weather and climate events such as severe thunderstorms, heat waves, floods, and droughts have profound impacts on human life, health, and socioeconomic well-being (e.g., Easterling et al. 2000). Precipitation extremes, because of their direct ties with other forms of hazards such as flooding and mudslides, often lead to significant death tolls and incur major financial losses over regions such as Europe (e.g., Zolina et al. 2004) and monsoonal East and Southeast Asia (e.g., Wang and LinHo 2002; Zhao and Yang 2014; Zhao et al. 2015). In the United States, flooding events associated with mesoscale convective systems (MCSs) and tropical/extratropical cyclones are also responsible for substantial life and property loss in many portions of the continental United States (Rauber et al. 2005).

Supplemental information related to this paper is available at the Journals Online website: http://dx.doi.org/10.1175/JCLID-15-0910.s1.

Corresponding author e-mail: Yi Deng, yi.deng@eas.gatech.edu
Numerous studies have examined the dynamical triggers and synoptic organization of heavy precipitation events in the United States. For example, Mo et al. (1997) showed that during boreal summer heavy precipitation events in the central United States tend to be manifested as a band extending from the tropical eastern Pacific through the Gulf of Mexico into the North Atlantic. Higgins et al. (1997) clarified the role of the Great Plains low-level jet (LLJ) and its associated anomalous moisture transport on the diurnal cycle and spatial distribution of precipitation over the central United States during spring-summer. Over the southwestern United States, heavy precipitation episodes are often embedded within the large-scale flow of the North American summer monsoon (Adams and Comrie 1997). Lau and Weng (2002) used singular value decomposition (SVD) to examine the dominant patterns of the summer precipitation over the United States. Lau and Weng's (2002) results showed that the precipitation anomalies over the northern Great Plains and Midwest are negatively correlated to midtropospheric height anomalies over the eastern and southeastern United States. During boreal winter, extreme precipitation (rain and snow) events over the western United States are typically 
driven by landfalling and bypassing coastal cyclones with origins extending back to the North Pacific storm track (e.g., Chang et al. 2002; Myoung and Deng 2009; Deng and Jiang 2011; Jiang and Deng 2011; Jiang et al. 2014). Winter precipitation over the western United States is also modulated by anticyclonic wave breaking during $\mathrm{La}$ Niña events and cyclonic wave breaking during El Niño events (Ryoo et al. 2013). Bradbury et al. (2003) demonstrated that rain and snow over the northeastern United States are closely tied to midlatitude cyclones occurring along the East Coast of the United States and the northern boundary of the Gulf Stream.

Global climate models have been found to possess reasonably good skill in simulating the precipitation distribution over the United States. Fourteen global climate models from phase 5 of the Coupled Model Intercomparison Project (CMIP5) were evaluated for their simulation of the cool season precipitation over the northeastern United States (Sheffield et al. 2013a). The results showed that the north-south variation of precipitation is well captured by the multimodel ensemble (MME) mean, with the Community Climate System Model, version 4 (CCSM4; Gent et al. 2011), generally performing best in representing precipitation over this region. Sheffield et al. (2013a) also found that models better simulate the number of heavy precipitation days in the southwestern and south-central United States compared to the southeastern United States. The observed positive trend in annual precipitation over the eastern United States was captured by the MME mean despite the simulated trend magnitude being smaller than that observed over the period of 1930-2004 (Sheffield et al. 2013b). Previous studies have also specifically evaluated the performance of the CCSM4 in simulating U.S. precipitation. For example, Cook et al. (2012) showed that the CCSM4 properly represented the basic circulation features and associated precipitation of the North American monsoon. The CCSM4 also well represents the observed zonal gradients in precipitation duration and intensity over the western United States (DeFlorio et al. 2013). Wehner et al. (2010) found that lower horizontal resolutions substantially reduce the model's accuracy in simulating extreme precipitation rates over the continental United States. Wehner (2013) introduced several error metrics to quantify the models' average biases in precipitation statistics (e.g., mean values, average maxima daily precipitation, and 20-yr return value of the daily precipitation).

The fidelity of precipitation characteristics in a global model is crucial for assessing the regional hydrological impact of climate change as recent studies suggest increasing probabilities in the occurrence of extreme precipitation events over the United States in association with ongoing global climate change (e.g., Groisman et al. 1999, 2005; Kunkel et al. 2003, 2010, 2013; Changnon et al. 2006; Asadieh and Krakauer 2015). Specifically, Karl and Knight (1998) showed that during the period 1910-95 precipitation has increased by about $10 \%$ across the United States, most likely owing to the growing numbers of heavy and extreme precipitation events. Hennessy et al. (1997) found that when atmospheric carbon dioxide is doubled in a global climate model the precipitation intensity for 1 -yr return period events in the United States increases by $10 \%-25 \%$, while for a fixed precipitation intensity, the corresponding return period also becomes shorter. Meehl et al. (2005) illustrated that increasing atmospheric water vapor and transport associated with atmospheric circulation changes may contribute to increases in precipitation intensity over northwestern and northeastern North America in the SRES A1B scenario.

A lot of studies have shown that extreme precipitation events are related to large-scale meteorological patterns (LMPs) that have spatial scales greater than mesoscale $\left(10^{4}-10^{5} \mathrm{~m}\right)$ but smaller than planetary scale $\left(10^{7} \mathrm{~m}\right)$. Here the LMPs that connect with precipitation extremes include atmospheric blocking events and cutoff low pressure systems as well as some synoptic-scale disturbance such as cyclones and anticyclones. Since LMPs are generally responsible for creating the conditions critical for precipitation extremes (e.g., moisture transport, excitation of mesoscale circulations, and interaction with local topography), it is expected that a model's skill in properly simulating regional precipitation characteristics crucially depends on its capability to capture the structure, magnitude, and occurrence frequency of the responsible LMPs driving the precipitation events (e.g., Fritsch et al. 1986; Bowden et al. 2013; Rudari et al. 2005).

Adopting this perspective, our current study aims to systematically and objectively delineate and document the fundamental extreme precipitation patterns (EPPs) that typically occur over the continental United States along with their associated LMPs and anomalous moisture transport patterns. The classification of the EPPs is based upon the spatial coverage of extreme daily precipitation rate over the United States during the boreal warm and cool seasons, respectively. The LMPs corresponding to each EPP are constructed from compositing daily circulation anomalies, and "base functions" created from these LMPs are used to define new metrics for evaluating the skill of, and inferring sources of bias for, extreme precipitation representation in global climate models (e.g., the CCSM4). The rest of this paper is organized as follows. Datasets and analysis 
methods used are described in section 2. Section 3 presents the fundamental EPPs along with the associated LMPs and anomalous moisture transport patterns during the boreal warm season for both observations and the CCSM4 simulation. The counterpart results for the boreal cool season are reported in section 4 . Section 5 discusses the development of new LMP-based metrics for evaluating and understanding the climate model representation of U.S. EPPs. Additional discussion and a summary are provided in section 6 .

\section{Data and methodology}

\section{a. Data}

The main observational dataset used in this study is the daily precipitation rate from the National Oceanic and Atmospheric Administration (NOAA) Climate Prediction Center (CPC) with a horizontal resolution of $0.25^{\circ}$ longitude by $0.25^{\circ}$ latitude over the continental United States $\left(20^{\circ}-50^{\circ} \mathrm{N}, 55^{\circ}-130^{\circ} \mathrm{W}\right)$ (Chen et al. 2008). This study also uses the daily mean geopotential height, zonal and meridional winds, and specific humidity from the National Centers for Environmental Prediction-National Center for Atmospheric Research (NCEP-NCAR) reanalysis, which has a resolution of $2.5^{\circ}$ longitude by $2.5^{\circ}$ latitude and 17 pressure levels in the vertical ranging from 1000 to $10 \mathrm{hPa}$ (Kalnay et al. 1996). The CCSM4 model from CMIP5 is atmosphereocean coupled, with a resolution of $1.25^{\circ}$ longitude by $0.94^{\circ}$ latitude and eight pressure levels in the vertical ranging from 1000 to $10 \mathrm{hPa}$. The output from the CCSM4's historical climate experiments (ensemble member r6i1p1) is compared with the observations for the same period (1950-2005). Because of differences in grid resolutions between the observation and the model output, the data are transformed to a common grid prior to the analysis. Specifically, for the precipitation data, we coarsen the observational data (which is of higher resolution) to the CCSM4 grid. The analysis of accompanying circulation anomalies is performed at the resolution of the NCEP-NCAR reanalysis data. The analyses throughout the study are performed separately for two seasons: the boreal warm season (MarchAugust) and cool season (September-February).

\section{b. Definition of extreme precipitation events}

Anomalous precipitation days are first defined at each grid point in the following manner: if the daily precipitation anomaly (deviation from the long-term daily climatology) at the grid point exceeds $+2.0 \sigma$ (sigma, the standard deviation in daily mean precipitation for the calendar day), we classify that day as an anomalous precipitation day. This classification is performed for all days (1950-2005) and each grid point over the continental United States. To identify extreme precipitation events having substantial regional impact, we additionally require that for any single day the number of grid points exceeding the precipitation anomaly threshold must exceed 5\% of the total number of grid points in the continental United States. Such days are classified as extreme precipitation events. The U.S. gridded normalized precipitation anomaly for the days marked as extreme precipitation events serve as the input for a cluster analysis (described later) to identify distinct EPPs. The duration of each EPP episode is defined as the number of consecutive days over which a single type of EPP occurs. We denote episodes of 1-day duration as dur-1 events and of 2-day duration as dur-2 events and so on. The mean duration for each EPP is expressed as follows:

$$
\text { mean }=\sum_{i=1}^{N}\left(n_{\mathrm{dur}-i} \times i\right) / \sum_{i=1}^{N}\left(n_{\mathrm{dur}-i}\right) .
$$

In Eq. (1), $i$ refers to the duration of individual episodes (with $N$ being the maximum duration for each EPP class) and $n_{\mathrm{dur}-i}$ is the total number of events having the duration of $i$.

\section{c. Classification of extreme precipitation patterns}

Hierarchical clustering is then used to identify distinct EPPs occurring over the United States. Specifically, we employ Ward's minimum variance clustering criterion (Ward 1963; Kalkstein et al. 1987; Park et al. 2014; Zhao et al. 2016) in applying hierarchical clustering, which has been shown to perform best among all other criteria in classifying precipitation patterns to the east of the Rockies (Gong and Richman 1995). We begin by defining a set of "objects," where each object is the two-dimensional gridded field of precipitation on a day when at least $5 \%$ of the total grid points in the continental United States are considered to be "extreme." We can essentially think of an object as a vector $\mathbf{P}$ consisting of $N_{d}$ elements with each element being the normalized precipitation anomaly for each grid point considered (and $N_{d}$ is the total number of grid points in our analysis domain, a constant throughout the analysis). A "cluster" is subsequently defined as an ensemble of similar objects. In the beginning of the cluster analysis, each cluster only contains one object. We apply Ward's method to compute the distance between two clusters (e.g., clusters $p$ and $q$ ). Ward's distance between clusters $p$ and $q$ is the difference between the sum of the two clusters' error sum of squares (ESS), and the ESS for the newly formed 
(a1) Cluster 1
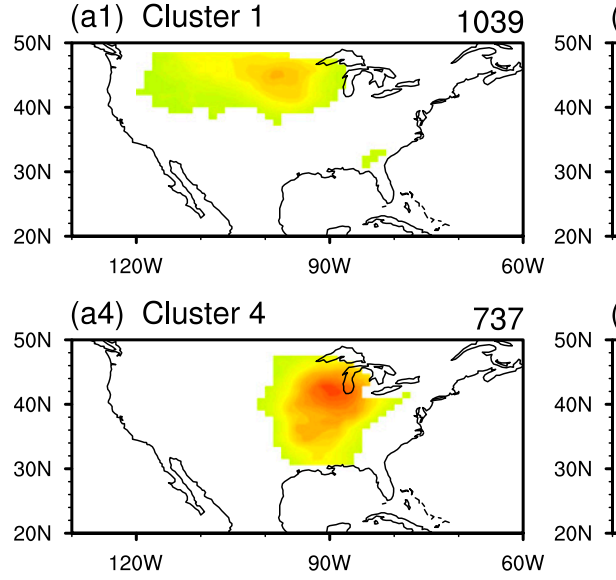

(a2) Cluster 2

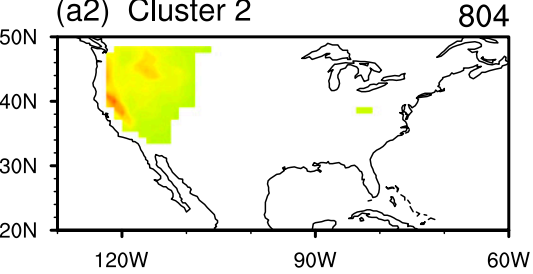

(a5) Cluster 5

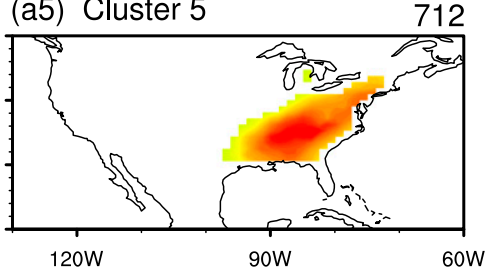

(b1) Cluster 1

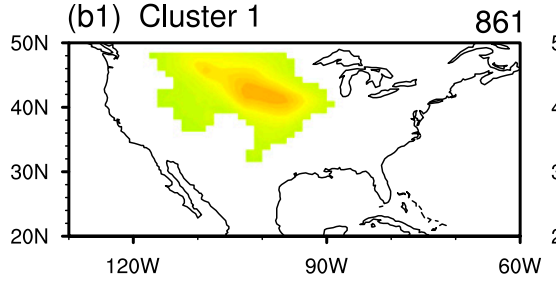

861

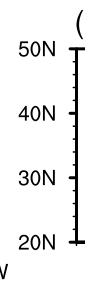

(b2) Cluster 2

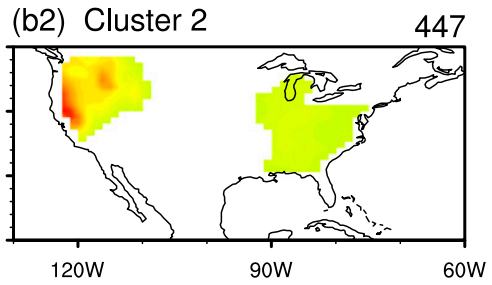

447

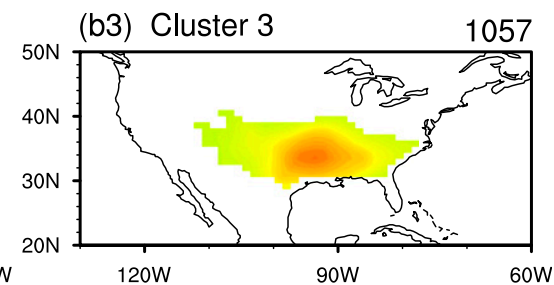

(b4) Cluster 4

655

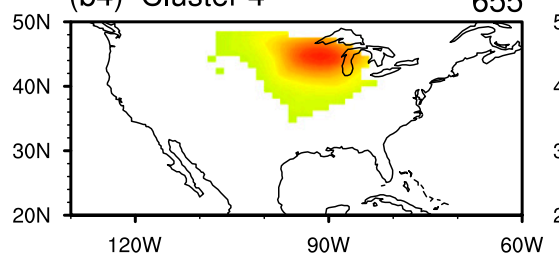

(b5) Cluster 5

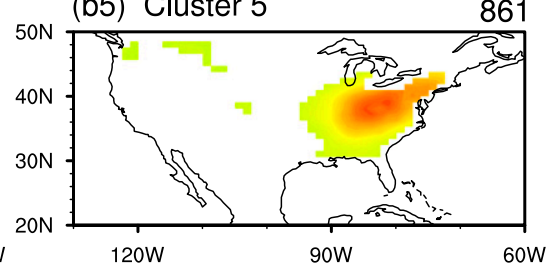

(b6) Cluster 6

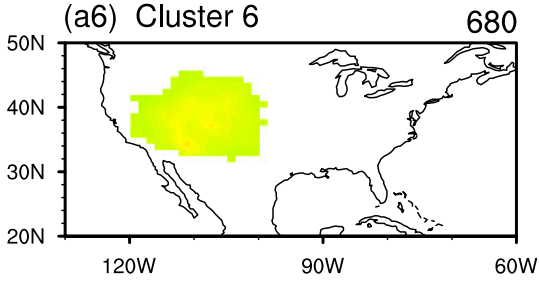

(a3) Cluster 3

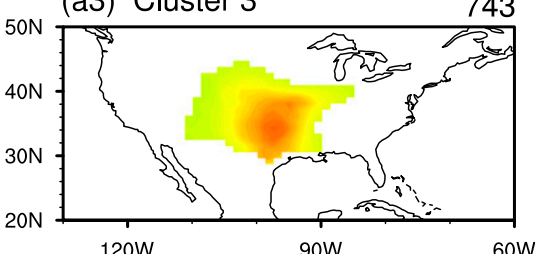

(a6) Cluster 6

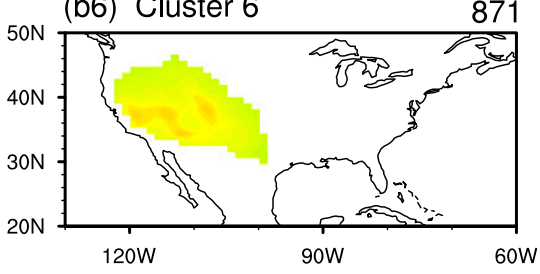

$9 \quad 10$

FIG. 1. (a1)-(a6) Composite daily precipitation anomalies $\left(\mathrm{mm} \mathrm{day}^{-1}\right)$ for the six warm season extreme precipitation clusters identified in the observation during the period 1950-2005. (b1)-(b6) The counterpart results obtained from the CCSM4 historical climate simulation. Only values significant at the 0.01 level are plotted. The number shown at the upper right of the figure is the occurrence frequency.

cluster $p q$. The ESS for an individual cluster is defined as follows:

$$
\mathrm{ESS}=\sum_{n=1}^{k}\left|\mathbf{P}_{n}-\overline{\mathbf{P}}\right|^{2}
$$

In Eq. (2), $k$ is the total number of objects (vectors) in a cluster and $\overline{\mathbf{P}}$ is the "center," or "mean," of the cluster. Ward's distance may be expressed as follows:

$$
d_{p, q}=\mathrm{ESS}_{p q}-\mathrm{ESS}_{p}-\mathrm{ESS}_{q}
$$

it is calculated for each pair of clusters. The first cluster merger occurs for the two clusters having the smallest Ward's distance. After this initial merging, the total number of clusters decreases by one.

The same procedure (i.e., computing Ward's distance, finding the smallest distance, and merging) is then sequentially repeated for each new group of clusters. As the process of merging continues, there will be one step where a significant "jump" in the smallest Ward's distance occurs, which means that the two clusters merged at this step have the most distinct structure or are the least "similar," and therefore they should not be merged. The clustering analysis is then terminated immediately after the previous step, and the number of clusters obtained after the previous step is considered to be the final number of the clusters identified. Following this procedure, we identify a total of six (five) clusters of U.S. extreme precipitation events for the warm (cool) season, in both the observations and the CCSM4 simulations. These clusters are defined as the so-called EPPs.

To test the robustness of the EPPs identified from observations, we conduct sensitivity experiments by perturbing the 1) duration of the warm season (March-August vs April-July) and cool season (September-February vs 
TABLE 1. List of the observed and simulated occurrence frequency and mean duration day (see the main text for definitions), spatial correlation of the composite precipitation/LMP anomalies between the observation and model, and predefined region of the LMP for the six precipitation clusters in the warm season. The occurrence frequency difference and relative difference between the observation and model are defined as (CCSM4 - CPC) and [(CCSM4 - CPC)/CPC $\times 100 \%]$, respectively.

\begin{tabular}{|c|c|c|c|c|c|c|}
\hline Cluster & $\begin{array}{l}\text { CPC No. of days } \\
\text { (mean duration) }\end{array}$ & $\begin{array}{c}\text { CCSM4 No. } \\
\text { of days } \\
\text { (mean duration) }\end{array}$ & $\begin{array}{c}\text { No. of } \\
\text { days difference } \\
\text { (relative difference) }\end{array}$ & $\begin{array}{l}\text { Observed-model } \\
\text { precipitation } \\
\text { correlation }\end{array}$ & $\begin{array}{l}\text { Observed-model } \\
\text { LMP correlation }\end{array}$ & LMP region \\
\hline 1 & $\begin{array}{l}1039 \\
(1.42)\end{array}$ & $\begin{array}{l}861 \\
(1.32)\end{array}$ & $\begin{array}{l}-178 \\
(-17 \%)\end{array}$ & 0.86 & 0.91 & $30^{\circ}-60^{\circ} \mathrm{N}, 150^{\circ}-60^{\circ} \mathrm{W}$ \\
\hline 2 & $\begin{array}{l}804 \\
(1.54)\end{array}$ & $\begin{array}{r}447 \\
(1.35)\end{array}$ & $\begin{array}{l}-357 \\
(-44 \%)\end{array}$ & 0.95 & 0.83 & $30^{\circ}-60^{\circ} \mathrm{N}, 150^{\circ}-100^{\circ} \mathrm{W}$ \\
\hline 3 & $\begin{array}{l}743 \\
(1.42)\end{array}$ & $\begin{array}{l}1057 \\
\quad(1.62)\end{array}$ & $\begin{array}{l}+314 \\
(+42 \%)\end{array}$ & 0.84 & 0.83 & $25^{\circ}-60^{\circ} \mathrm{N}, 140^{\circ}-75^{\circ} \mathrm{W}$ \\
\hline 4 & $\begin{array}{l}737 \\
(1.22)\end{array}$ & $\begin{array}{l}655 \\
(1.25)\end{array}$ & $\begin{array}{l}-82 \\
(-11 \%)\end{array}$ & 0.79 & 0.93 & $25^{\circ}-55^{\circ} \mathrm{N}, 130^{\circ}-50^{\circ} \mathrm{W}$ \\
\hline 5 & $\begin{array}{l}712 \\
(1.34)\end{array}$ & $\begin{array}{l}861 \\
(1.32)\end{array}$ & $\begin{array}{l}+149 \\
(+21 \%)\end{array}$ & 0.84 & 0.97 & $25^{\circ}-55^{\circ} \mathrm{N}, 130^{\circ}-50^{\circ} \mathrm{W}$ \\
\hline 6 & $\begin{array}{l}680 \\
(1.46)\end{array}$ & $\begin{array}{l}871 \\
(1.53)\end{array}$ & $\begin{array}{l}+191 \\
(+28 \%)\end{array}$ & 0.88 & 0.81 & $25^{\circ}-60^{\circ} \mathrm{N}, 140^{\circ}-90^{\circ} \mathrm{W}$ \\
\hline
\end{tabular}

October-January), 2) threshold criterion defining an extreme precipitation grid point ( 2 standard deviations vs 1.5 standard deviations), 3) minimum areal coverage (over the United States) required for an extreme precipitation day ( $5 \%$ vs $7.5 \%$ ), and 4 ) the analysis domain of the study (expanding to $10^{\circ}-70^{\circ} \mathrm{N}, 50^{\circ}-170^{\circ} \mathrm{W}$ by using the precipitation data from the CCSM4 historical climate simulation). The results from these sensitivity experiments are all qualitatively similar to those presented in sections 3 and 4 despite slight changes in the ranking of individual clusters when the analysis domain is significantly expanded (please see the supplemental material for more details of the sensitivity experiments). Additionally, when a similar analysis is done for "ordinary precipitation" (precipitation rate $\geq 2 \mathrm{~mm} \mathrm{day}^{-1}$ ), geographically similar clusters are found, suggesting that the regional mechanisms of extreme precipitation are similar to that of ordinary precipitation.

\section{Observed and simulated extreme precipitation events in the warm season}

\section{a. Precipitation clusters}

When applied to the observed warm season extreme precipitation events, the hierarchical clustering results in six distinct EPPs for the continental United States. The cluster mean daily precipitation anomaly is shown in Figs. 1a(1)-(6) (in which only anomalies that are statistically significant at the 0.01 level, according to Student's $t$ test, are plotted). In other words, for each cluster mean pattern, if the $t$ value at one grid point is larger than $t_{0.01}$ (which is the $t$ value when the $p$ value equals 0.01 ), the cluster mean precipitation anomaly at this grid point is significant at the 0.01 level. The first precipitation cluster is located over the upper Midwest and has the highest occurrence frequency (1039 days) among the six clusters (Table 1). Clusters 2 and 6 [Figs. $1 \mathrm{a}(2)$ and $1 \mathrm{a}(6)$, respectively] are associated with anomaly patterns located over, respectively, the northwestern and southwestern United States, which are both weaker in magnitude than the other four clusters. Cluster 5 is characterized by the largest precipitation anomalies $\left(>9 \mathrm{~mm} \mathrm{day}^{-1}\right)$ that extend northeastward from Louisiana, Missouri, and Alabama and cover virtually all the southeast of the Great Lakes [Fig. 1a(5)]. The remaining two clusters capture warm season EPPs occurring over the southern Great Plains [cluster 3; Fig. 1a(3)] and the central-lower Midwest [cluster 4; Fig. 1a(4)], as found in Higgins et al. (1997) and Mo et al. (1997). The precipitation anomalies in both of these two clusters exceed $7 \mathrm{~mm}$ day $^{-1}$. The precipitation event duration is as important as the maximum precipitation rate (e.g., Brommer et al. 2007; Brommer 2012). Figure 2 (blue bars) displays the distribution of the normalized occurrence frequency of extreme precipitation days as a function of the duration for each EPP shown in Fig. 1a. During the warm season, dur- 1 events account for $60 \%-$ $80 \%$ of the total number of events for each cluster. This number drops rapidly to around $20 \%$ for dur- 2 events. The dominance of short-duration events (i.e., 1-2 days) is consistent with the convective nature of precipitation during the warm season. The precipitation events having the longest and shortest mean duration are found to be cluster 2 (1.54 days) and cluster 4 (1.22 days), respectively (see Table 1).

Figure $1 \mathrm{~b}$ shows the corresponding precipitation anomaly patterns for EPPs derived from the CCSM4 historical climate simulations. The EPP occurrence frequency is well simulated for clusters $1,4,5$, and 6 , 
(a) Cluster 1

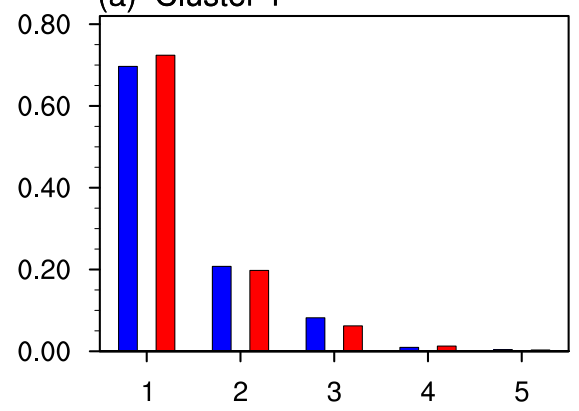

(c) Cluster 3

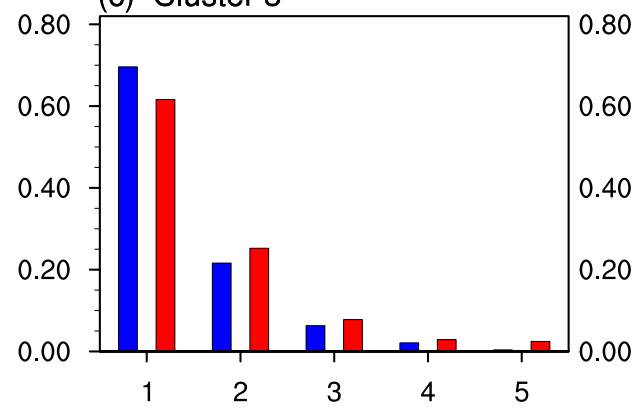

(e) Cluster 5

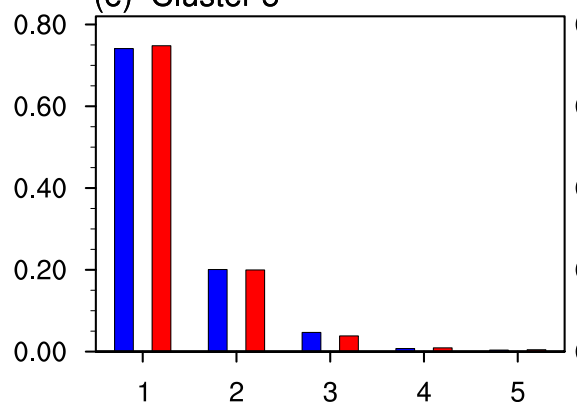

(b) Cluster 2

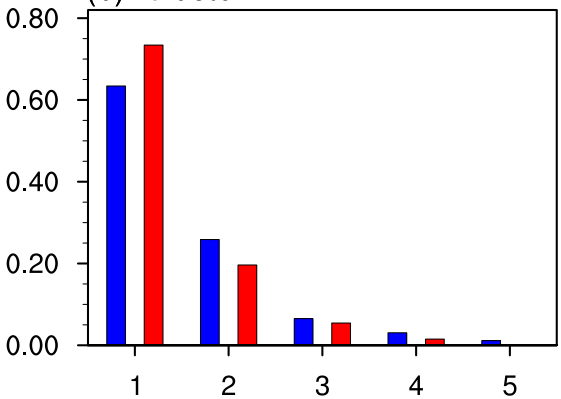

(d) Cluster 4

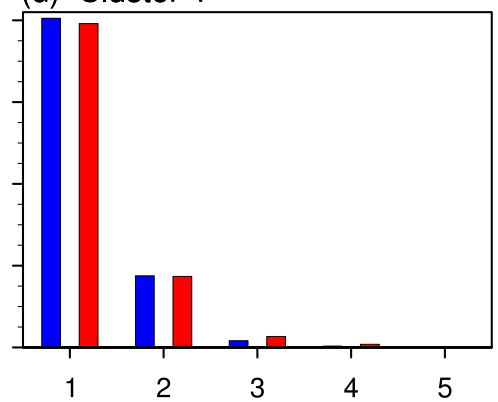

(f) Cluster 6

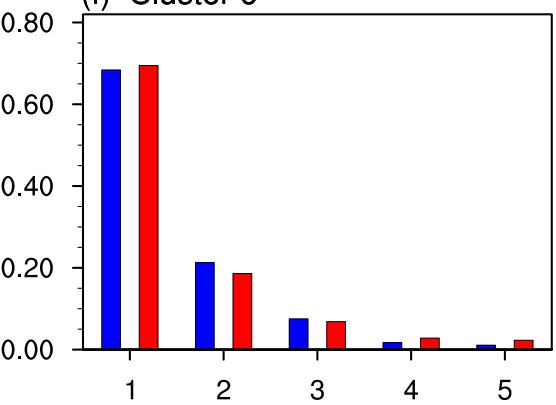

FIG. 2. Distribution of the normalized occurrence frequency as a function of event duration (days) for the six identified clusters of precipitation extremes in the warm season. Blue and red bars indicate the observation and the CCSM4 simulation, respectively.

while that of cluster 2 (cluster 3 ) is considerably underestimated (overestimated) by the model (Table 1). In terms of the spatial pattern, the CCSM4 generally well simulates the six observed EPPs. This validates the model's capability of capturing major patterns of warm season extreme precipitation over the United States. The spatial correlation coefficient between the observed and simulated composite precipitation anomaly pattern (in a domain of $20^{\circ}-50^{\circ} \mathrm{N}, 60^{\circ}-130^{\circ} \mathrm{W}$ ) for each cluster (i.e., Fig. 1a vs Fig. 1b) is also included in Table 1. Clusters 2 and 4 (extreme precipitation over the northwestern United States and the central-lower Midwest) have the highest (0.95) and lowest (0.79) correlation coefficients, respectively. This difference is clearly reflected in the spatial patterns of the extreme precipitation events simulated by the model. In Fig.
$1 \mathrm{~b}(2)$, the maximum precipitation anomaly associated with the model cluster 2 is located over the northwestern United States, consistent with the corresponding maxima in observations [Fig. 1a(2)]. However, the model cluster 4 has precipitation anomalies extending to the upper Midwest instead of southward as for observations [Fig. 1b(4) vs Fig. 1a(4)]. In terms of duration (Fig. 2, red bars), the CCSM4 clusters are also dominated by dur- 1 and dur- 2 events that account for $60 \%-80 \%$ and $20 \%$, respectively, of the total number of events across the six clusters. This is in good agreement with observations despite the fact that the model slightly overestimates (underestimates) dur-1 events for cluster 2 (cluster 3). It is worth noting that for both clusters 2 and 3 the biases in the number of dur- 1 events are to a certain degree compensated for by biases in the number of dur- 2 
(a1) Cluster 1

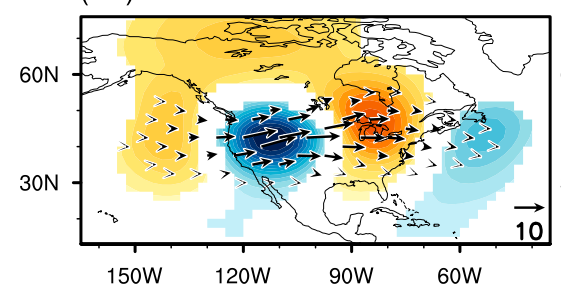

(a4) Cluster 4

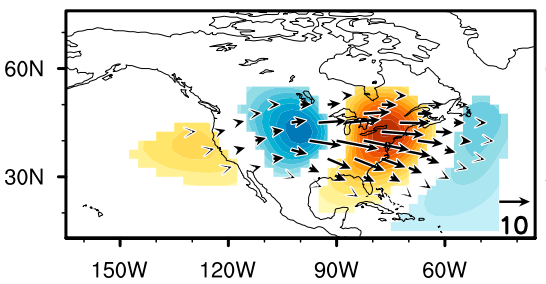

(b1) Cluster 1

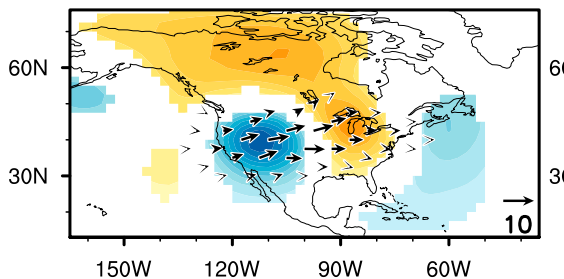

(b4) Cluster 4

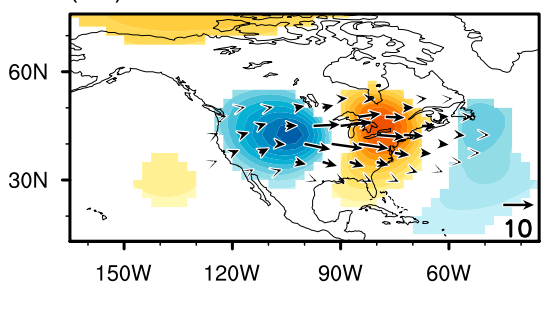

(a2) Cluster 2

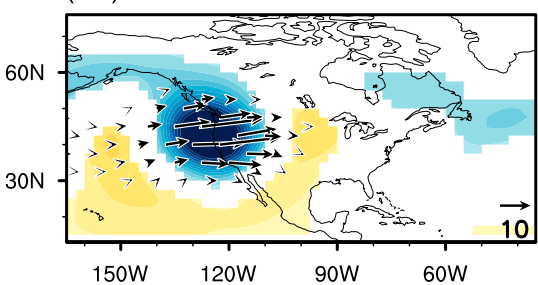

(a5) Cluster 5

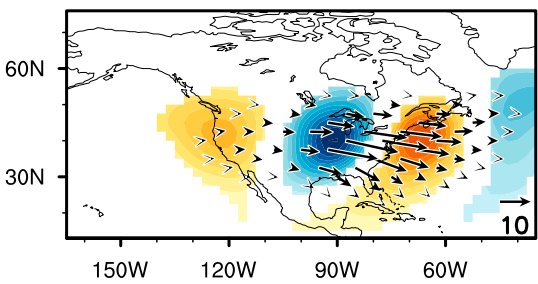

(b2) Cluster 2

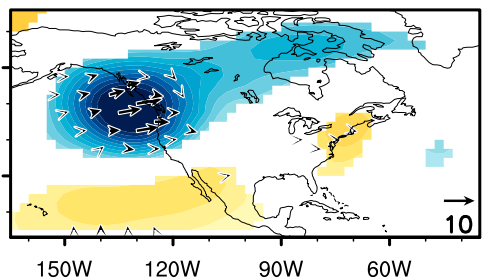

(b5) Cluster 5

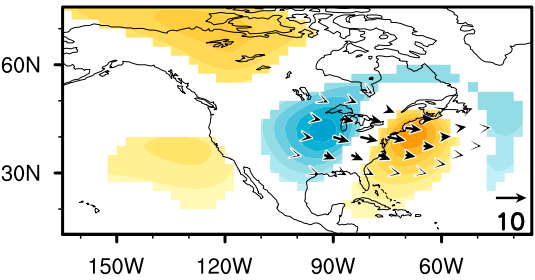

(a3) Cluster 3

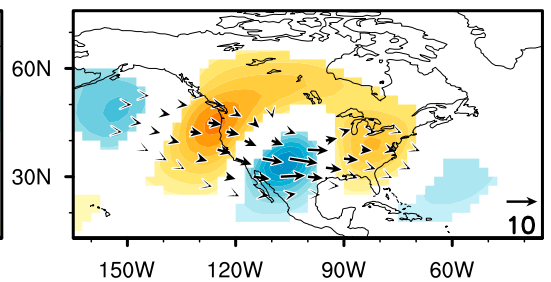

(a6) Cluster 6

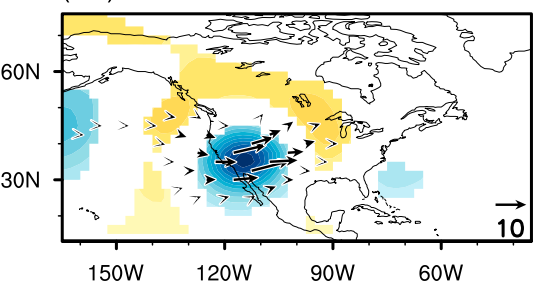

(b3) Cluster 3

$\begin{array}{lllllllllllll}-60 & -50 & -40 & -30 & -20 & -10 & 0 & 10 & 20 & 30 & 40 & 50 & 60\end{array}$

FIG. 3. As in Fig. 1, but for geopotential height (m) plus wave-activity flux $\mathbf{W}$ (vectors, $\mathrm{m}^{2} \mathrm{~s}^{-2}$ ) at $500 \mathrm{hPa}$.

events, and this suggests that the model has reasonable skill in simulating these short-duration events.

\section{b. LMPs and moisture transport associated with precipitation clusters}

In this step, we assess composite circulation anomalies to identify the canonical LMPs associated with each U.S. EPP during the warm season. Following earlier studies demonstrating a close linkage between geopotential height $Z$ anomalies (defined as total $Z$ minus the daily climatology) at $500 \mathrm{hPa}(Z-500)$ and precipitation anomalies (e.g., Tomozeiu et al. 2005; Luterbacher et al. 2007), in Fig. 3 we plot the composite $Z-500$ anomalies and the associated horizontal wave-activity flux for the six observed (Fig. 3a) and simulated (Fig. 3b) EPP clusters. According to Takaya and Nakamura (2001), the horizontal component of the wave-activity flux vector $\mathbf{W}$ may be expressed as follows:

$\mathbf{W}=\frac{p}{2|U|}\left[\begin{array}{c}U\left(\Psi_{x}^{\prime 2}-\Psi^{\prime} \Psi_{x x}^{\prime}\right)+V\left(\Psi_{x}^{\prime} \Psi_{y}^{\prime}-\Psi^{\prime} \Psi_{x y}^{\prime}\right) \\ U\left(\Psi_{x}^{\prime} \Psi_{y}^{\prime}-\Psi^{\prime} \Psi_{x y}^{\prime}\right)+V\left(\Psi_{x}^{\prime 2}-\Psi^{\prime} \Psi_{y y}^{\prime}\right)\end{array}\right]$,

where $\Psi^{\prime}$ stands for the perturbation streamfunction $\left(\Psi_{x}^{\prime}=v^{\prime}, \Psi_{y}^{\prime}=-u^{\prime}\right) ; U$ and $V$ are the daily climatological mean zonal and meridional winds, respectively; $|U|$ is, in turn, the magnitude of the winds $\left(=\sqrt{\left(U^{2}+V^{2}\right)}\right)$; and $p=($ pressure/1000 hPa $)$. In addition, we display composite anomalies in the 700-hPa moisture flux ( $u q, v q ; q$ is the specific humidity and anomalies defined as total flux minus the daily climatological flux) to illustrate the source region of moisture for each EPP and 
(a1) Cluster 1

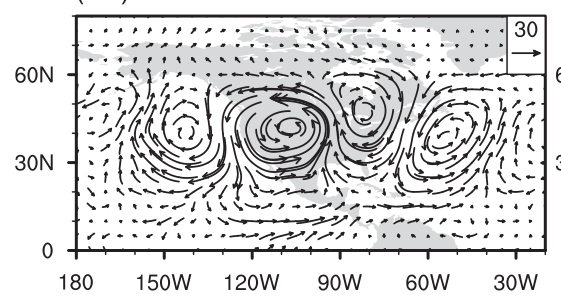

(a4) Cluster 4 (a2) Cluster 2

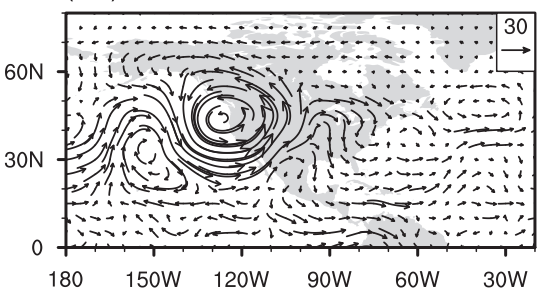

(a5) Cluster 5 (a3) Cluster 3

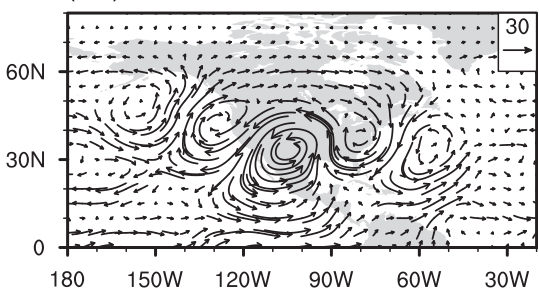

(a6) Cluster 6
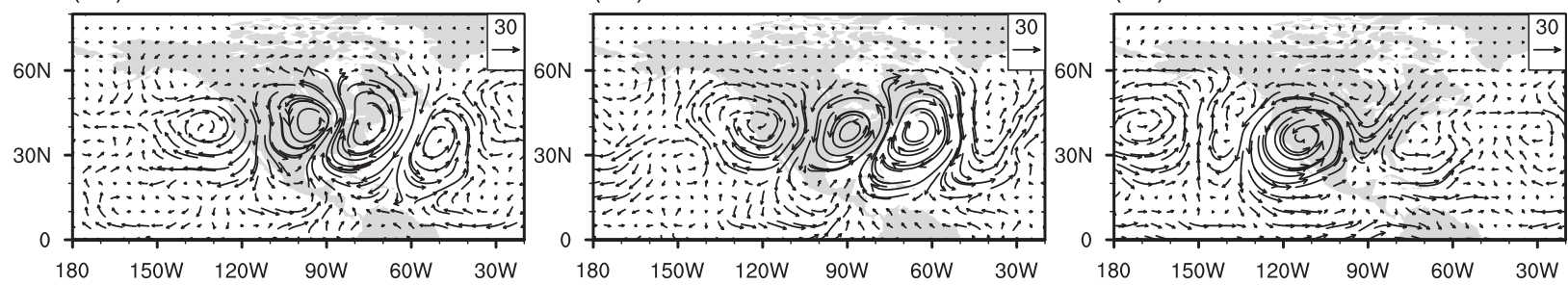

(b1) Cluster 1

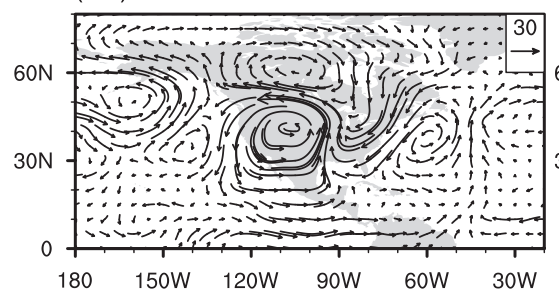

(b2) Cluster 2

(b3) Cluster 3
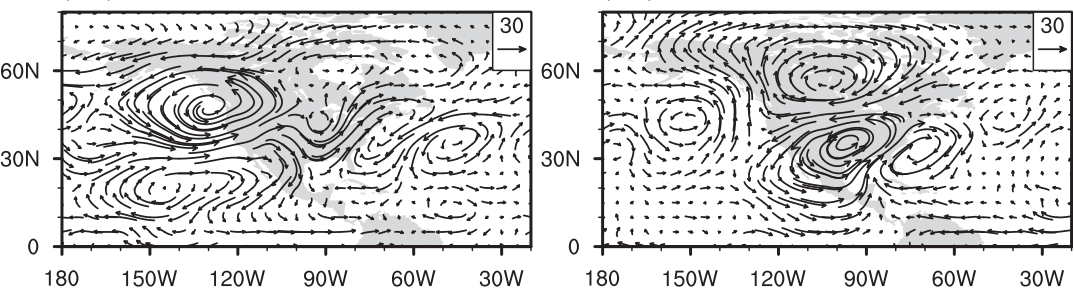

(b4) Cluster 4

(b5) Cluster 5
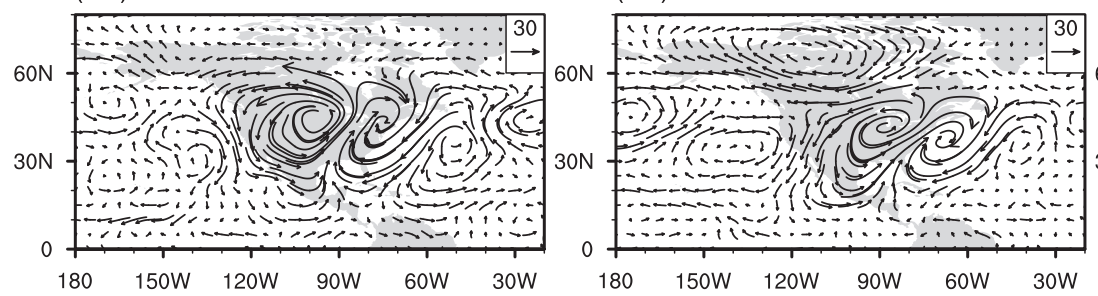

(b6) Cluster 6

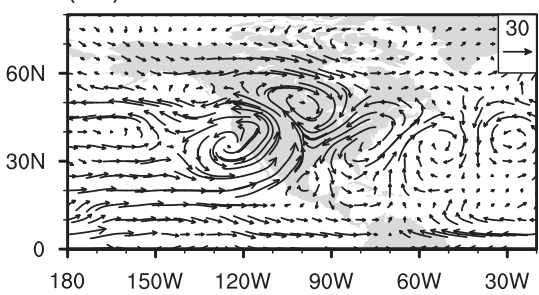

FIG. 4. As in Fig. 1, but for moisture flux anomalies [uq, vq; curly vectors: $\left.1 \times 10^{-4} \mathrm{~kg} \mathrm{~kg}^{-1} \mathrm{~m} \mathrm{~s}^{-1}\right]$ at $700 \mathrm{hPa}$.

its connection to the corresponding LMP in Fig. 4 (Mo 2000; Berbery 2001).

Figure $3 \mathrm{a}(1)$ shows that, for cluster 1, a Rossby wave train originating from the eastern North Pacific is responsible for the enhanced precipitation occurring over the upper Midwest [cluster 1; Fig. 1a(1)], consistent with the close relationship between Rossby wave packets and the regional precipitation (e.g., Feldstein and Dayan 2008; Wang et al. 2010; Holman et al. 2014). The marked negative height anomaly feature over the western United States and positive height anomaly feature farther east are accompanied, respectively, by lower-tropospheric cyclonic and anticyclonic circulations leading to a strong horizontal convergence of moisture over the upper Midwest [Fig. 4a(1)]. The Z-500 anomaly patterns for clusters 2 [Fig. 3a(2)] and 6 [Fig. 3a(6)] appear more local in origin with only weak remote forcing evident.
The low-level moisture convergence pattern [Figs. $4 a(2),(6)]$ is consistent with the locations where extreme precipitation is found. Similar to cluster 1 , cluster 5 is also characterized by a zonal wave train [Fig. 3a(5)]. The strongly enhanced moisture convergence over the southeast coast of the United States [Fig. 4a(5)] is the result of moisture transport from both the Gulf of Mexico and North Atlantic (Mo et al. 1997) and leads to the large precipitation anomalies found in this cluster. Similar to clusters 1 and 5, Rossby wave propagation from the North Pacific seems to play an important role in forcing the extreme precipitation events in clusters 3 and 4 [Figs. 3a(3),(4)]. The difference between the two clusters is that the wave activity originates from a higher latitude and propagates southeastward in cluster 3 , while the wave pattern in cluster 4 originates from near the U.S. West Coast, exhibits stronger downstream 
(a1) Cluster 1

(a2) Cluster 2
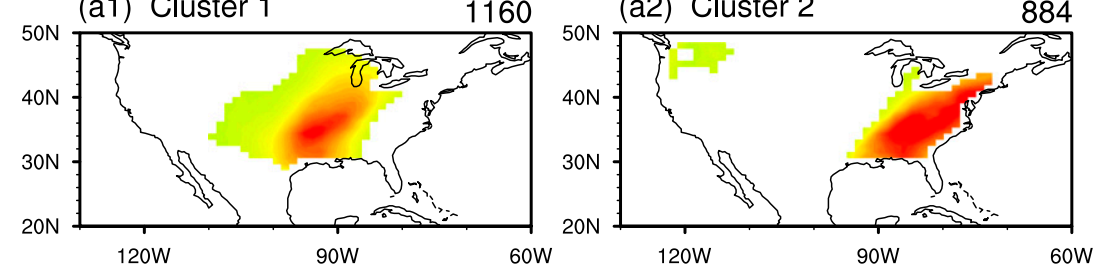

(a5) Cluster 5
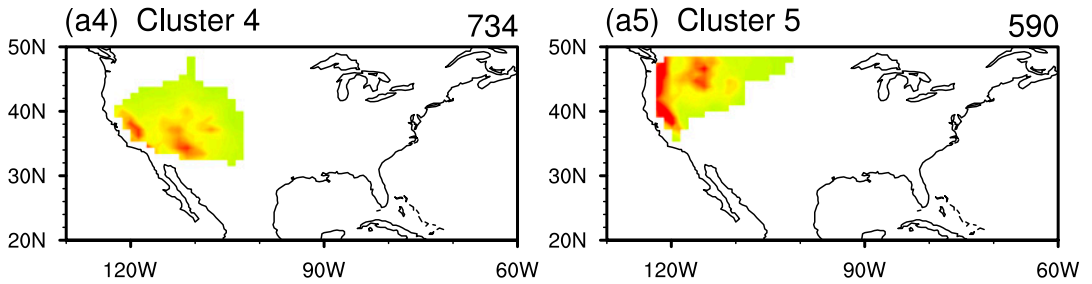

(b1) Cluster 1

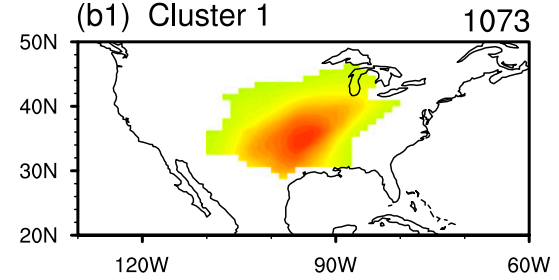

(b2) Cluster 2

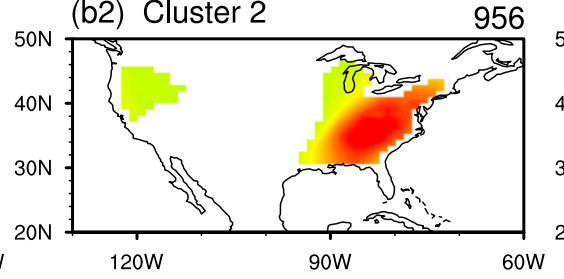

(b3) Cluster 3

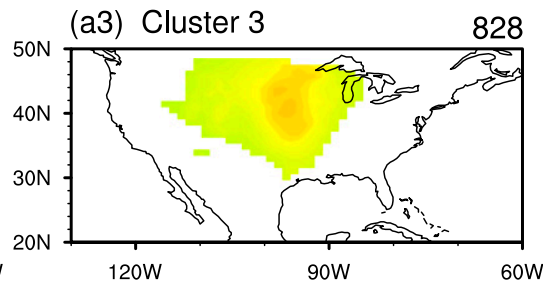

$60 \mathrm{~W}$
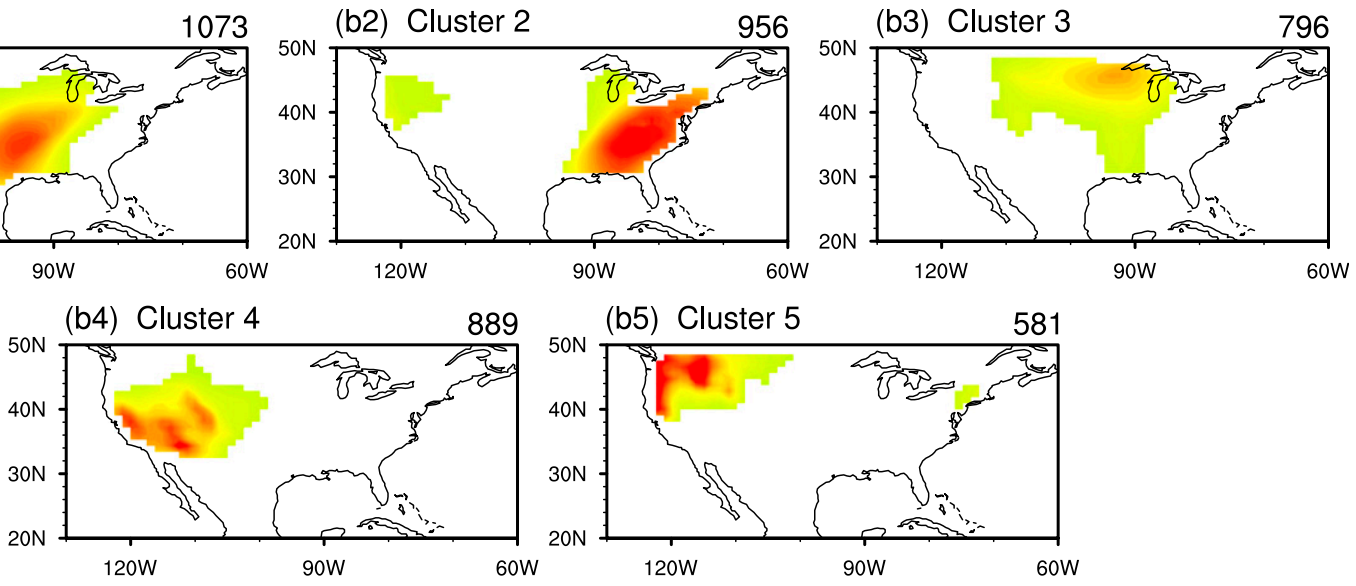

(b5) Cluster 5
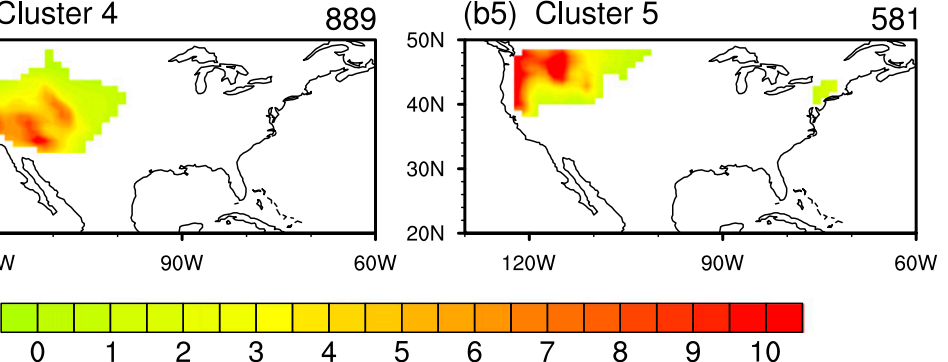

FIG. 5. As in Fig. 1, but for the cool season (and without cluster 6).

development, and follows a more zonal path. The corresponding local moisture convergence is also weaker in cluster 3 compared to cluster 4 [Figs. 4a(3),(4)]. These results illustrate the critical role of LMPs and their associated moisture flux anomalies in the formation of regional precipitation extremes.

Figures $3 \mathrm{~b}$ and $4 \mathrm{~b}$ present the corresponding extreme precipitation LMPs and moisture flux anomaly patterns obtained from the CCSM4 clusters. The spatial correlation coefficient between the observed and simulated LMPs (in a domain of $20^{\circ}-70^{\circ} \mathrm{N}, 35^{\circ}-165^{\circ} \mathrm{W}$; Fig. $3 \mathrm{a}$ vs Fig. $3 b$ ) is computed for each cluster and summarized in Table 1 . Clusters 1,4 , and 5 have relatively high correlation coefficients (above 0.90 ) while clusters 2,3 , and 6 have lower correlations (between 0.81 and 0.83 ). For those clusters with high correlation coefficients, the model well represents both the LMP spatial patterns [Figs. 3b(1),(4),(5)] and the corresponding moisture flux anomaly patterns [Figs. 4b(1),(4),(5)]. For the remaining clusters with lower LMP correlation coefficients, the model-simulated LMP and anomalous moisture fluxes are either spatially shifted [cluster 2; Figs. $3 \mathrm{~b}(2)$ and $4 \mathrm{~b}(2)$ ], completely distorted (cluster 3; Figs. 3b(3) and 4b(3)], or weak in magnitude [cluster 6; Figs. 3b(6) and 4b(6)]. Note that the wave-activity flux is not well simulated by the model in most clusters (except for cluster 4), indicating a less satisfactory performance of the CCSM4 in capturing the wave packet source/sink region than of representing the relevant LMPs.

It is interesting to note that for cluster 2 the EPP is simulated quite well (spatial correlation of 0.95 ) while the corresponding LMP is more poorly simulated (spatial correlation of 0.83 ). A contrasting example is cluster 4 where the CCSM4 LMP representation is better than that of the corresponding EPP (0.93 vs 0.79 ). This disconnection between the model simulation of the EPP and the corresponding LMP likely reflects the relative importance of model resolution/physics in determining extreme precipitation events compared to large-scale dynamics. For example, the heavy precipitation events 
(a1) Cluster 1

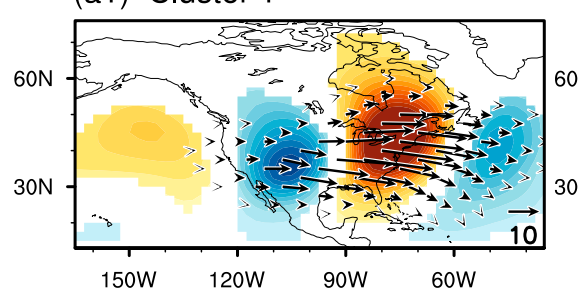

(a4) Cluster 4 (a2) Cluster 2

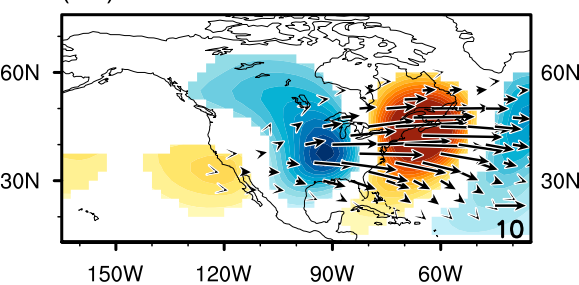

(a3) Cluster 3

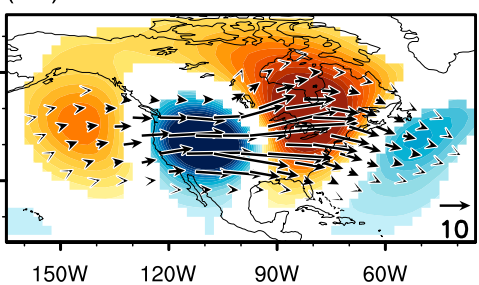

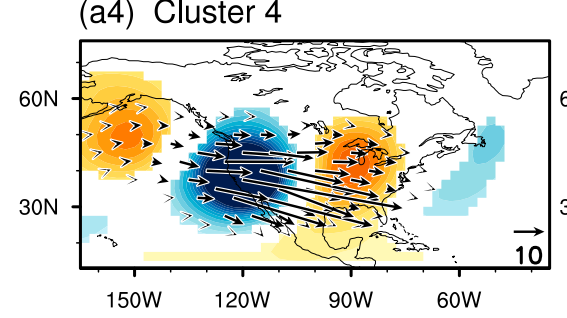

(a5) Cluster 5

(b2) Cluster 2

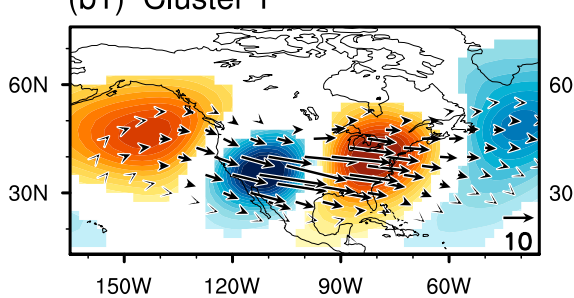

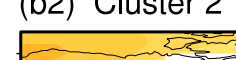

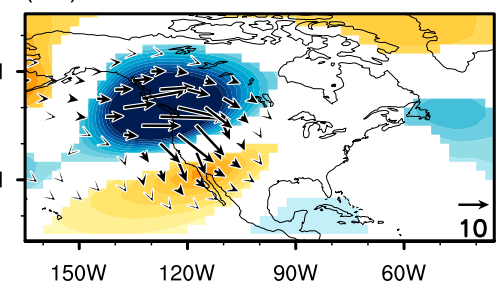

(b3) Cluster 3

(b4) Cluster 4

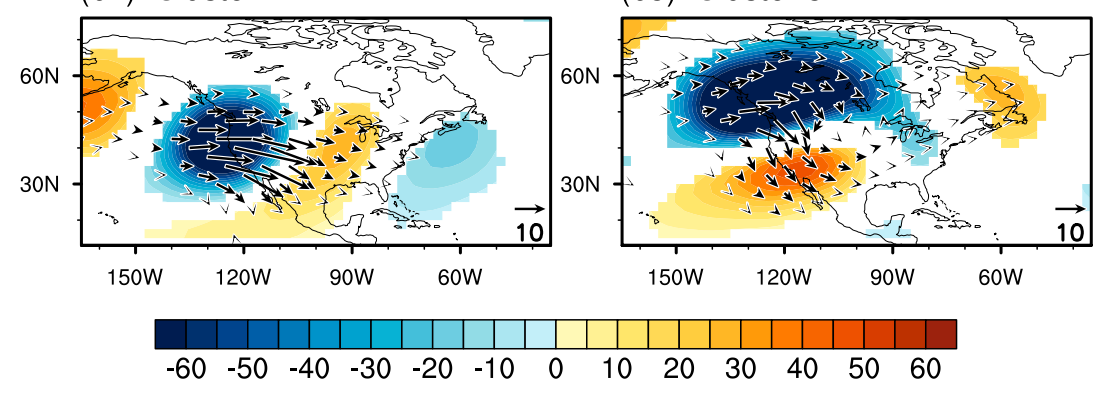

FIG. 6. As in Fig. 3, but for the cool season (and without cluster 6).

captured by cluster 2 are significantly influenced by local terrain features in the Pacific Northwest while the model representation of topographic precipitation is known to be highly resolution dependent (e.g., Sperber et al. 1994; Leung and Qian 2003; Rojas 2006). Given the regionally dominant role of topography, it is quite possible for the model to have a less than perfect representation of the LMP while providing an accurate EPP as long as the model has sufficiently high resolution to resolve the main topographic features in this region. Cluster 4 is a contrasting example; because of the dominant convective nature of the warm season precipitation over the central-lower Midwest (e.g., Hilgendorf and Johnson 1998; Anderson and Arritt 2001) and the greater importance of model-parameterized physics (including convection, cloud microphysics, and boundary layer processes; e.g., Marshall et al. 1997; Iorio et al. 2004), the CCSM4 provides a less satisfactory representation of the actual magnitude and distribution of the extreme precipitation (e.g., those associated with spring-summer MCSs) despite a good performance in simulating the relevant LMP.

\section{Observed and simulated extreme precipitation events in the cool season}

Figure 5a shows the five observed EPPs for the cool season, noting that four (clusters 1, 2, 4, and 5) resemble patterns identified in Schubert et al. (2008). Clusters 1 and 2 are both southwest-northeast-oriented precipitation anomaly patterns with maximum anomalies exceeding 
(a1) Cluster 1

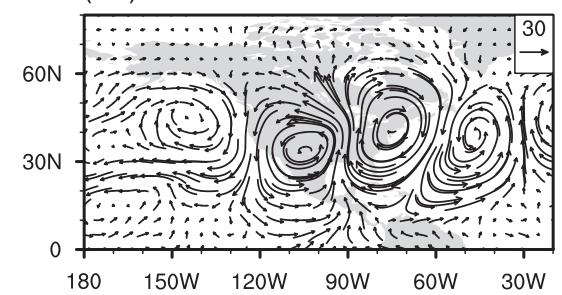

(a4) Cluster 4 (a2) Cluster 2

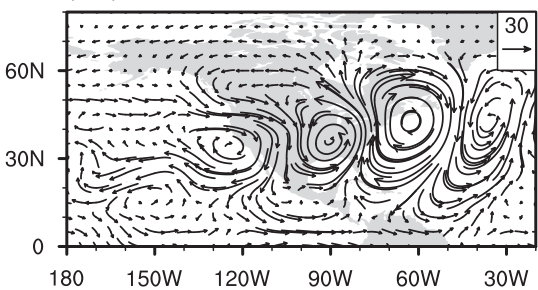

(a3) Cluster 3

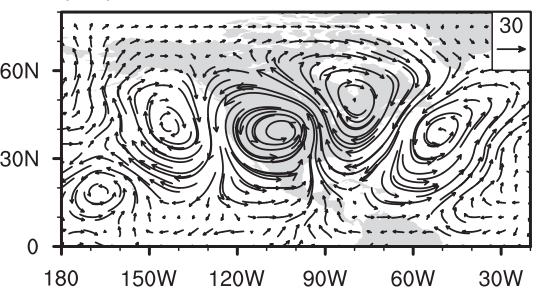

(a5) Cluster 5

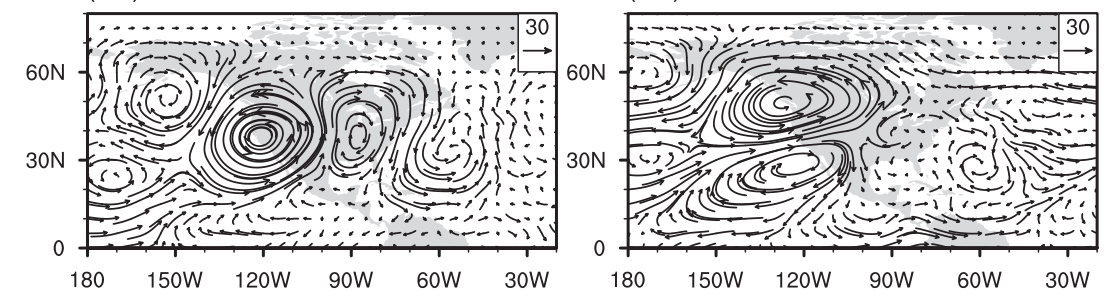

(b1) Cluster 1

(b2) Cluster 2

(b3) Cluster 3

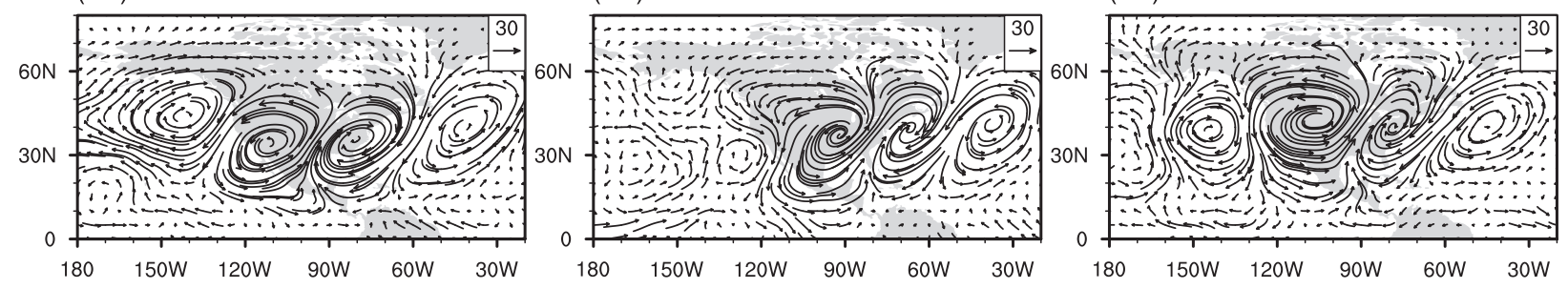

(b4) Cluster 4

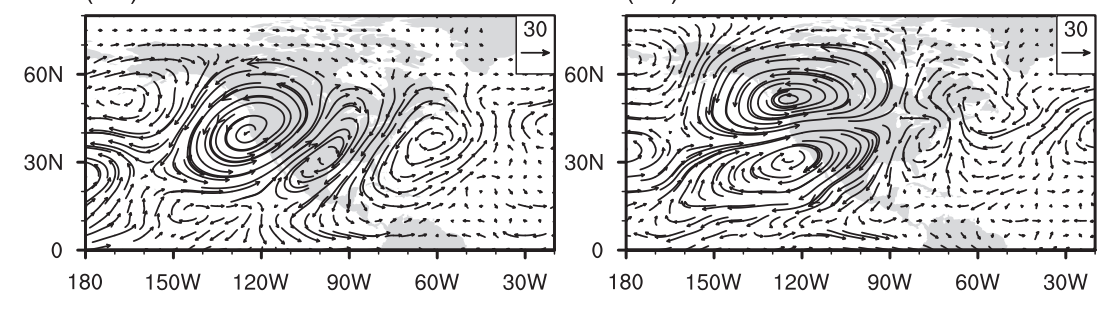

FIG. 7. As in Fig. 4, but for the cool season (and without cluster 6).

$9 \mathrm{~mm} \mathrm{day}^{-1}$ over the central plain and southern-eastern United States, respectively. These two clusters are likely related to winter cyclones forming in the Gulf of Mexico and along the coast of the Carolinas (e.g., Martin et al. 1995; Martin 1998), consistent with the presence of pronounced negative $Z-500$ anomaly features (shortwave troughs) within the corresponding LMP located to the west of the precipitation maxima [Figs. 6a(1),(2)] and cyclonic signatures in the anomalous moisture flux field (Figs. 7a(1),(2)). Cluster 3 exhibits a precipitation anomaly pattern that extends meridionally over the Midwestnorthern Great Plains with maximum anomalies near $5 \mathrm{~mm} \mathrm{day}^{-1}$ [Fig. 5a(3)]. This cluster is likely related to cyclogenesis east of the Rockies including so-called Alberta Clippers (Rauber et al. 2005). Similar to clusters 1 and 2, cluster 3 arises from Rossby wave propagation from the North Pacific to the North Atlantic but with a stronger wave flux development [Fig. 6a(3)]. The related low-level anomalous moisture convergence pattern leads to enhanced precipitation over the Midwest-northern Great Plains [Fig. 7a(3)]. Clusters 4 and 5 are clearly tied to coastal cyclones affecting the western United States during the cool season [Figs. 5a(4),(5)]. Cluster 5 corresponds to storms following the climatological storm track where the Pacific Northwest receives most of the precipitation, while Cluster 4 indicates an equatorward-shifted storm track in which cyclones make landfall or bypass California (e.g., during an El Niño winter) (Myoung and Deng 2009).

Figure $5 \mathrm{~b}$ shows the corresponding EPPs for the CCSM4 during the cool season. The model simulation of EPP occurrence frequency during the cool season is considerably better than for the warm season, particularly for clusters 1, 2, 3, and 5 (Table 2). The largest bias in occurrence frequency occurs for cluster 4 , which is 
TABLE 2. As in Table 1, but for the cool season.

\begin{tabular}{|c|c|c|c|c|c|c|}
\hline Cluster & $\begin{array}{c}\text { CPC No. of } \\
\text { days } \\
\text { (mean duration) }\end{array}$ & $\begin{array}{c}\text { CCSM4 } \\
\text { No. of days } \\
\text { (mean duration) }\end{array}$ & $\begin{array}{c}\text { No. of days } \\
\text { difference } \\
\text { (relative difference) }\end{array}$ & $\begin{array}{l}\text { Observed-model } \\
\text { precipitation } \\
\text { correlation }\end{array}$ & $\begin{array}{l}\text { Observed-model LMP } \\
\text { correlation }\end{array}$ & LMP region \\
\hline 1 & $\begin{array}{l}1160 \\
\quad(1.44)\end{array}$ & $\begin{array}{l}1073 \\
\quad(1.60)\end{array}$ & $\begin{array}{l}-87 \\
(-8 \%)\end{array}$ & 0.89 & 0.88 & $20^{\circ}-60^{\circ} \mathrm{N}, 160^{\circ}-40^{\circ} \mathrm{W}$ \\
\hline 2 & $\begin{array}{l}884 \\
(1.34)\end{array}$ & $\begin{array}{l}956 \\
(1.37)\end{array}$ & $\begin{array}{l}+72 \\
(-8 \%)\end{array}$ & 0.98 & 0.94 & $20^{\circ}-65^{\circ} \mathrm{N}, 130^{\circ}-30^{\circ} \mathrm{W}$ \\
\hline 3 & $\begin{array}{l}828 \\
(1.38)\end{array}$ & $\begin{array}{l}796 \\
(1.31)\end{array}$ & $\begin{array}{l}-32 \\
(-4 \%)\end{array}$ & 0.87 & 0.94 & $25^{\circ}-70^{\circ} \mathrm{N}, 160^{\circ}-40^{\circ} \mathrm{W}$ \\
\hline 4 & $\begin{array}{l}734 \\
(1.57)\end{array}$ & $\begin{array}{l}889 \\
(1.44)\end{array}$ & $\begin{array}{l}+155 \\
(+21 \%)\end{array}$ & 0.94 & 0.89 & $25^{\circ}-65^{\circ} \mathrm{N}, 165^{\circ}-75^{\circ} \mathrm{W}$ \\
\hline 5 & $\begin{array}{l}590 \\
(1.40)\end{array}$ & $\begin{array}{l}581 \\
(1.31)\end{array}$ & $\begin{array}{c}-9 \\
(-2 \%)\end{array}$ & 0.92 & 0.91 & $20^{\circ}-70^{\circ} \mathrm{N}, 150^{\circ}-90^{\circ} \mathrm{W}$ \\
\hline
\end{tabular}

overrepresented by CCSM4. The model also better simulates the EPP spatial patterns during the cool season with the highest (0.98) and lowest (0.87) spatial correlation coefficients found for clusters 2 and 3, respectively (Table 2). In addition, the durations of simulated cool season EPPs are reasonable (Fig. 8), noting that both observed and simulated durations are slightly larger during the cool season, consistent with more frequent persistent stratiform-type precipitation during the cool season (e.g., large-scale precipitation found ahead of the warm front in a cyclone).

The spatial correlation coefficients between the observed and simulated LMPs are near 0.90 for all five clusters (Table 2), indicating the good skill of the CCSM4 in simulating the large-scale dynamical processes (i.e., LMPs) responsible for cool season EPPs (Fig. 6b). Cluster 2 is best captured by the model in terms of both the EPP and corresponding LMP and anomalous moisture flux patterns [Figs. $6 b(2)$ and $7 b(2)$ ]. The consistency between excellent representations of both the precipitation and accompanying LMP indicates that large-scale dynamics controls the formation of extreme precipitation events over the southern/ eastern United States during the cool season. Similar to cluster 4 for the warm season, the relatively poor simulation of the cool season cluster 3 EPP is accompanied by a very good representation of the corresponding LMP [Fig. 6b(3)]. This again suggests that physical processes (the representation of which is problematic in global models) play a more important role in determining the characteristics of precipitation extremes over the Midwest. Cluster 4 , on the other hand, has a relatively poor representation of the LMP but a very good representation of the EPP, consistent with increased importance of topographically forced precipitation over the southwest mountainous region (see discussion of cluster 2 for the warm season). It is also interesting to note that the LMPs associated with all five cool season clusters exhibit wave train features of varying degrees (see wave-activity fluxes in
Fig. 6a and Fig. S12 in the supplemental material). This is consistent with the important role played by mobile upper-tropospheric disturbances in surface cyclogenesis during the cool season (Kitabatake 2002). These wave train features are well captured by the CCSM4 (Fig. 6b). Compared to the warm season, the waveactivity flux is better simulated by the model in the cool season.

\section{LMP-based metrics for evaluating model representation of precipitation extremes}

The results presented in the previous two sections illustrate the critical role played by LMPs in initiating and organizing distinct EPPs over the United States. Building upon such knowledge, here we define LMP-based metrics that, when applied to standard model output, can provide a simple and direct assessment of a model's potential in representing regional EPPs. The metric construction consists of two main steps. In step 1 , a "base function" is defined from the LMP corresponding to a selected EPP cluster (e.g., cluster 1 of the warm season). Such a base function is the observed cluster mean Z-500 anomaly pattern over a predefined region (see the rightmost columns of Tables 1 and 2) that encompasses all of the large-scale anomaly structure relevant for this cluster. In step 2, spatial correlations are computed between this base function and (separately) the observed and simulated daily $Z-500$ anomalies over the predefined region for all days during the season of interest. Completing these two steps, for any cluster under consideration, we obtain two daily indices: one is the daily spatial correlation coefficient for observations and the other is for the model simulation. We name the former the observed LMP index (OLMP) and the latter the simulated LMP index (MLMP).

Linear regression analysis is applied to estimate the linear relationship between daily index (e.g., OLMP) and daily precipitation anomaly for the season of 
(a) Cluster 1

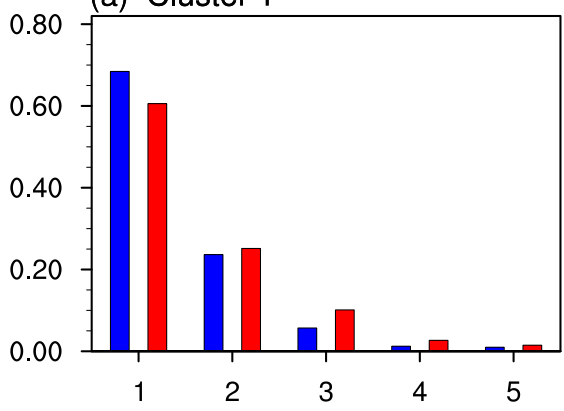

(c) Cluster 3

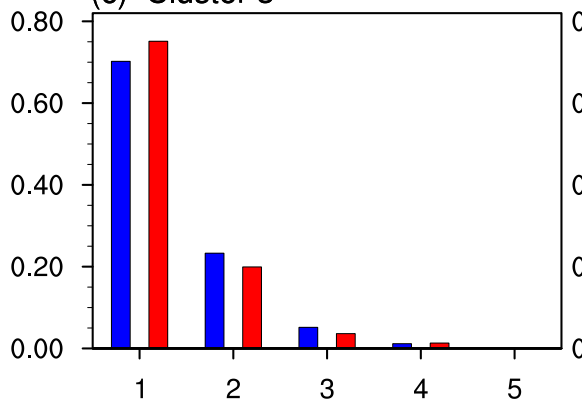

(b) Cluster 2

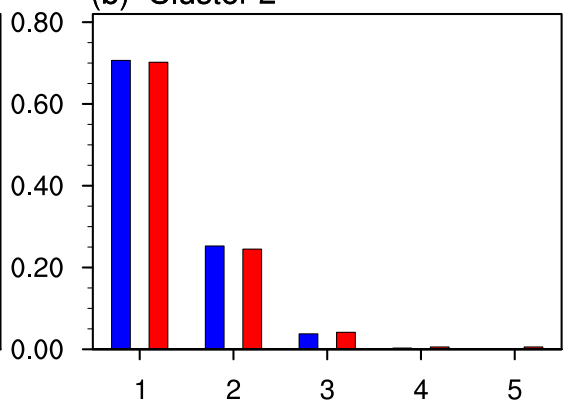

(d) Cluster 4

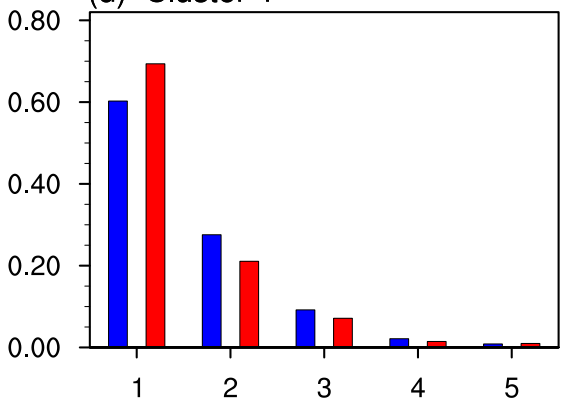

(e) Cluster 5

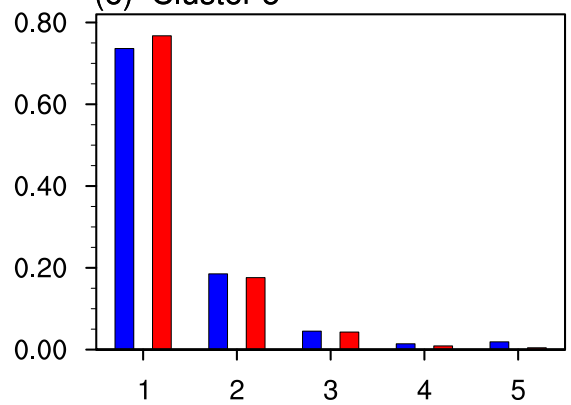

FIG. 8. As in Fig. 2, but for the cool season (and without cluster 6).

interest from 1950 to 2005 . Regressing the observed daily precipitation anomaly onto the corresponding OLMP, we successfully reproduce the spatial patterns for six (four) of the warm (cool) season EPP clusters, with cluster 3 of the cool season being an outlier [Fig. 9a (Fig. 10a) vs Fig. 1a (Fig. 5a)]. The generally good reconstruction of precipitation extremes suggests that as long as a certain type of LMP emerges, it is very likely to initiate and drive its corresponding precipitation extreme-the higher the value of the OLMP, the closer the precipitation anomaly pattern compares to that identified through the clustering analysis. Regressing the model-simulated daily precipitation anomaly onto the corresponding MLMP also recreates most of the EPP patterns (Fig. 9b vs Fig. 1a; Fig. 10b vs Fig. 5a). Note that larger discrepancies exist between the MLMP-regressed EPP and that in observations for cluster 4 (cluster 3 ) of the warm (cool) season
[Figs. 9b(4) and $10 \mathrm{~b}(3)$ ], consistent with our previous discussions of the greater importance of finer-scale physical processes (e.g., convection) in forming this EPP and potential issues in the model representation of these physical processes. In other words, even though the "correct" LMP occurs in a given day in the model (indicated by high MLMP value), the "correct" precipitation pattern does not fully emerge in the regressed pattern. We also note that the magnitude of the regression coefficients for the model is generally weaker than those of the observations, which is likely due to the use of the observed Z-500 LMP as the base function.

Figures 11 and 12 are the empirical probability distribution functions (PDFs) of the OLMP (blue curves) and MLMP (red curves) for all days in the warm and cool season, respectively, falling within each EPP category. The right tails of the PDFs (greater than 0.80) are emphasized here since large OLMP and MLMP values 
(a1) Cluster 1

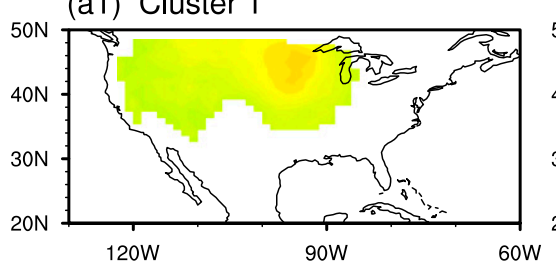

(a4) Cluster 4

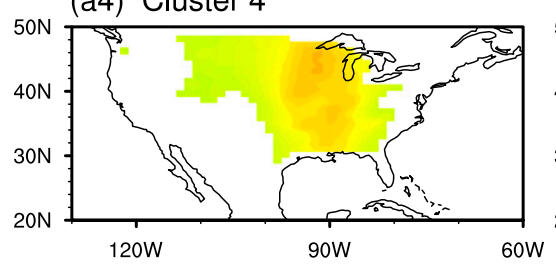

(b1) Cluster 1

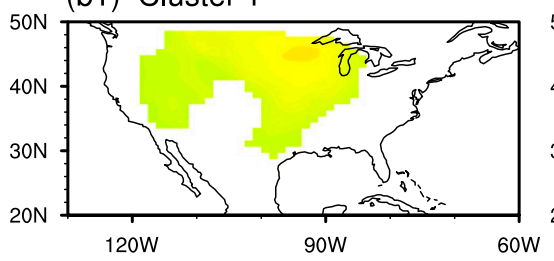

(b4) Cluster 4

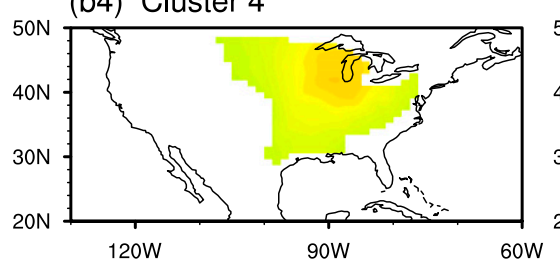

(a2) Cluster 2

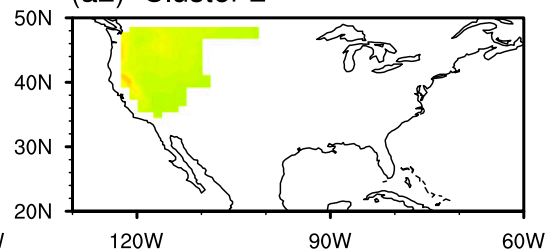

(a5) Cluster 5

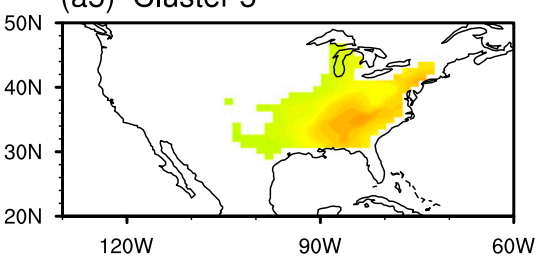

(b2) Cluster 2

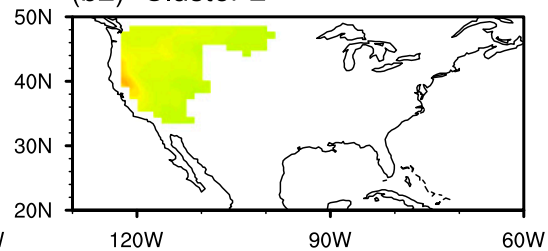

(b5) Cluster 5

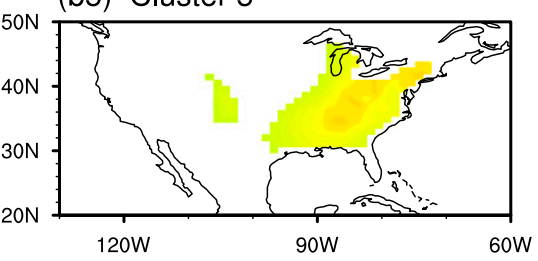

(a3) Cluster 3

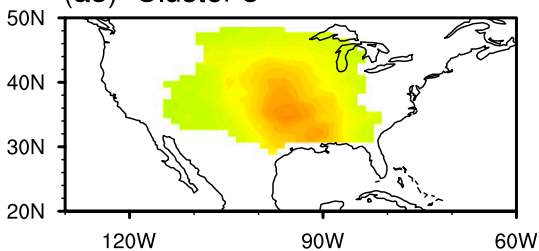

(a6) Cluster 6

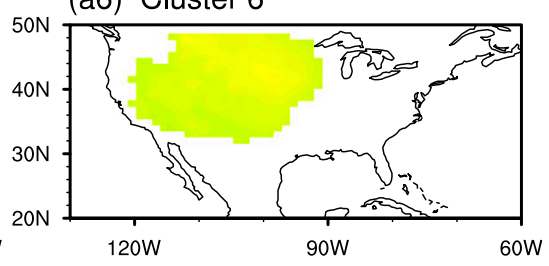

(b3) Cluster 3

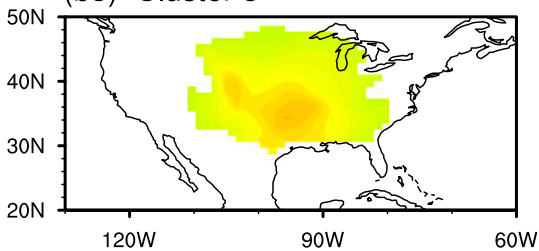

(b6) Cluster 6

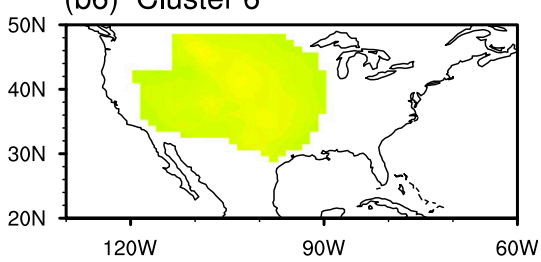

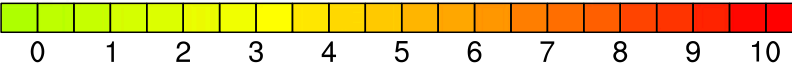

FIG. 9. (a) Regression of the observed daily precipitation anomalies ( $\mathrm{mm} \mathrm{day}^{-1}$ ) onto the OLMP (see the main text for definitions) corresponding to each of the six precipitation clusters in the warm season. (b) As in (a), except that the simulated daily precipitation anomalies are regressed upon the MLMP. Only values significant at the 0.01 level are plotted.

will be related to daily circulation anomalies highly resembling the cluster-specific LMPs (i.e., base functions) and thus provide direct measures of the occurrence chance for a specific EPP. The tails of the OLMP and MLMP PDFs are generally similar except for cluster 2 in the warm season and cluster 4 in the cool season. The negatively biased (red curve under blue curve in Fig. 11b) MLMP PDF for cluster 2 of the warm season clearly reflects an inadequate simulation of the occurrence frequency for the cluster 2 LMP in the CCSM4, consistent with a significantly underrepresented frequency of cluster 2 extreme precipitation days in the model (Table 1). In a similar manner, the positively biased MLMP PDF for cluster 4 of the cool season (Fig. 12d) is responsible for the substantial overestimation of cluster 4 precipitation frequency in the model (Table 2). These results demonstrate the value of the LMP-based metrics in providing an efficient means of assessing a model's capability in representing major extreme precipitation types prior to an explicit clustering analysis in the model.

\section{Summary and concluding remarks}

Regional patterns of extreme precipitation events occurring over the continental United States have been isolated via a seasonally stratified hierarchical cluster analysis of daily precipitation for the period 1950-2005. Six canonical EPPs are isolated for the boreal warm season and five for the cool season. The six warm season EPPs (clusters 1-6) correspond to precipitation extremes occurring, respectively, over the upper Midwest, northwestern United States, southern Great Plains, central-lower Midwest, southern-eastern United States, and southwestern United States. The five cool season EPPs (clusters 1-5) are related to extreme precipitation occurring, respectively, over the central plains, 
(a1) Cluster 1

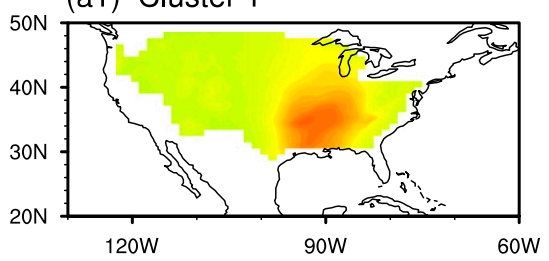

(a4) Cluster 4

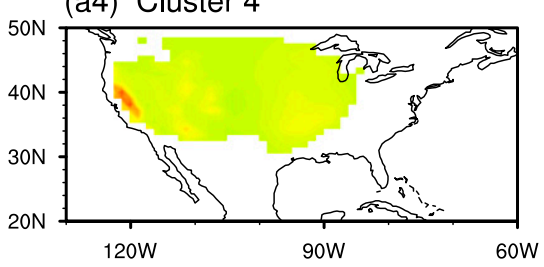

(a2) Cluster 2

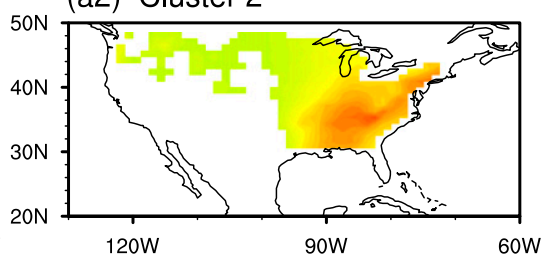

(a3) Cluster 3

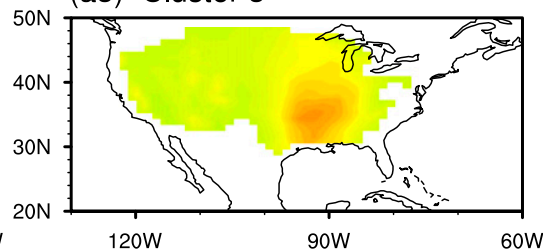

(a5) Cluster 5

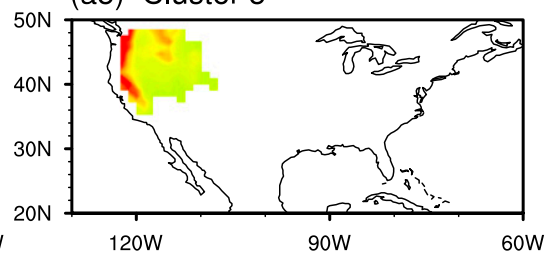

(b3) Cluster 3

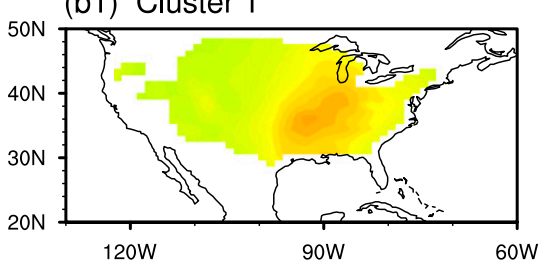

(b2) Cluster 2
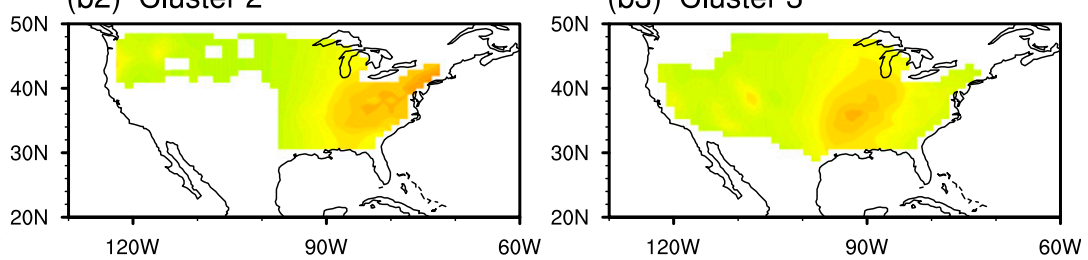

(b5) Cluster 5
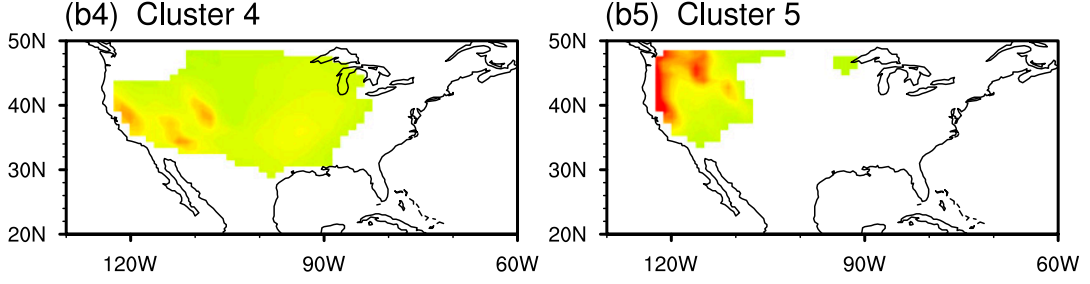

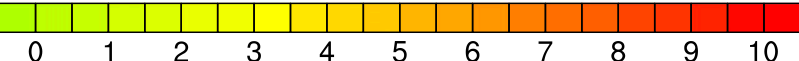

FIG. 10. As in Fig. 9, but for the cool season (and without cluster 6).

southern-eastern United States, Midwest-northern Great Plains, southwestern United States, and northwestern United States. Cluster-mean composites were constructed to isolate the associated 1) LMPs (defined in terms of 500-hPa height anomalies) and 2) anomalous lower-tropospheric moisture flux patterns for each EPP. The LMPs can be broadly divided into two categories: large-scale Rossby wave train structures and locally forced cyclonic-anticyclonic circulation anomalies. Despite the different dynamical origins of these LMPs, they all serve to initiate and maintain anomalous lowertropospheric moisture convergence directly into the regions of extreme precipitation.

For the study period (1950-2005), the CCSM4 historical climate simulation successfully reproduces the observed behavior of warm and cool season EPPs both in terms of spatial patterns and duration characteristics. This provides a useful decomposition of extreme precipitation events over the continental United States despite the differences in EPP ranking and the requirement of the similar domains for the observation and model. The mean duration of all EPP events is slightly shorter during the warm season than the cool season, consistent with more frequent convective precipitation in the former. The model's skill of representing a particular precipitation cluster tends to be positively correlated with its skill in representing the corresponding LMP. However, discrepancies between the model's capability in representing LMPs and precipitation clusters are found for EPPs occurring over the Pacific Northwest and centrallower Midwest during the warm season. The former is dominated by topographic precipitation, which renders the detailed LMP structure to be relatively less important than a reasonably good representation of terrain features in the model. The latter is characterized by convective precipitation and indicates a good representation of LMP structure does not guarantee a good simulation of precipitation since the importance of finer-scale physical processes (e.g., convection and boundary layer processes) is regionally and seasonally dependent and 
(a) Cluster 1

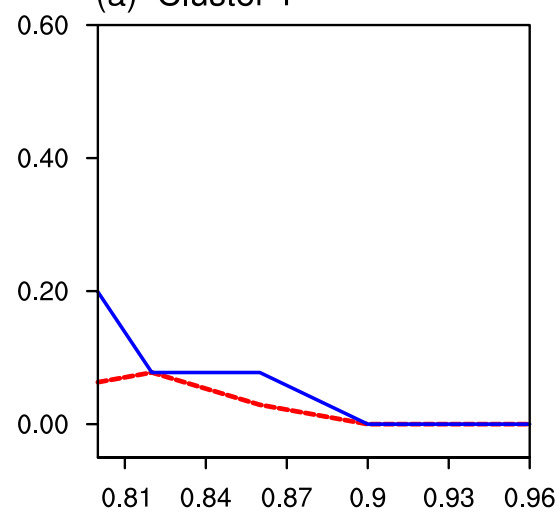

(c) Cluster 3

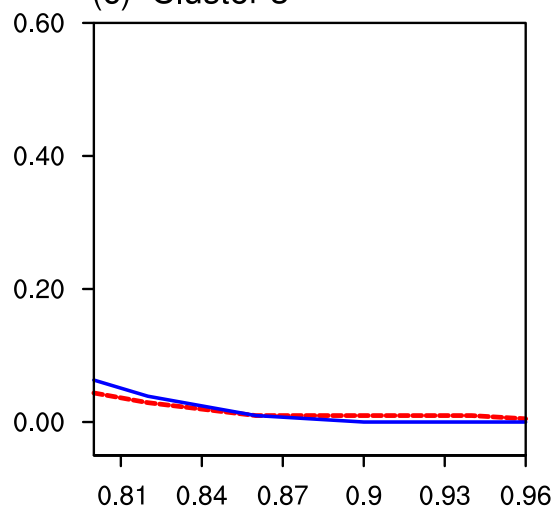

(e) Cluster 5

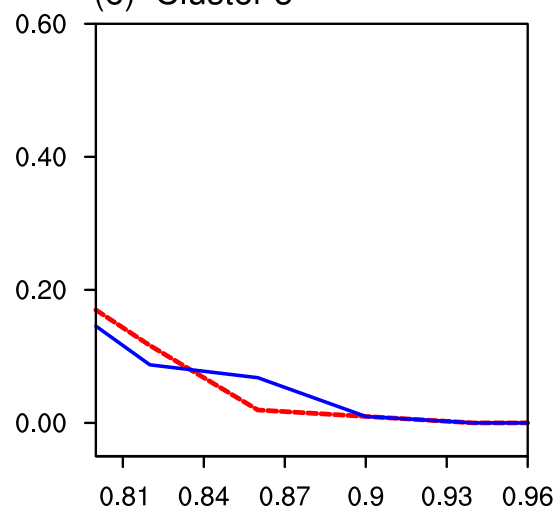

(b) Cluster 2

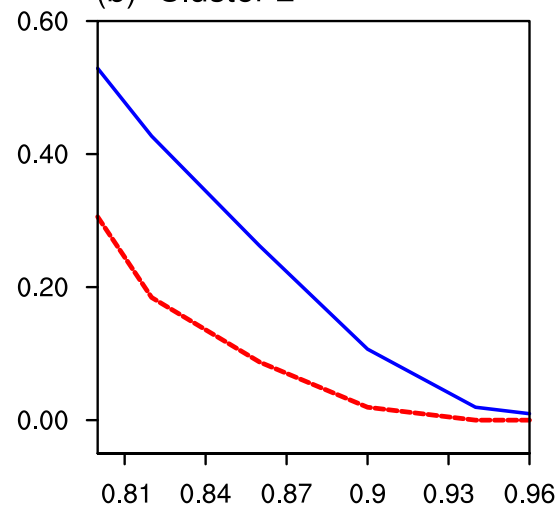

(d) Cluster 4

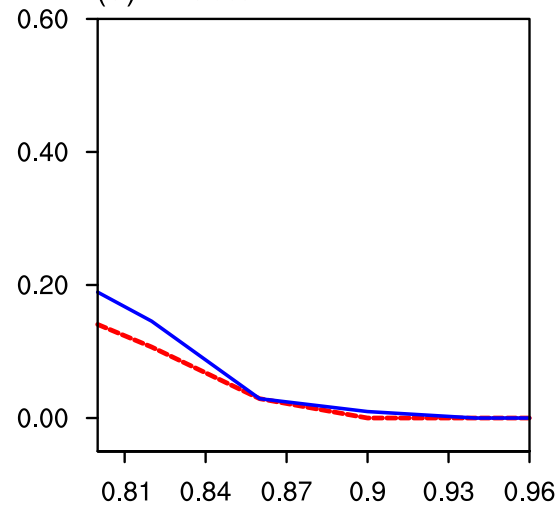

(f) Cluster 6

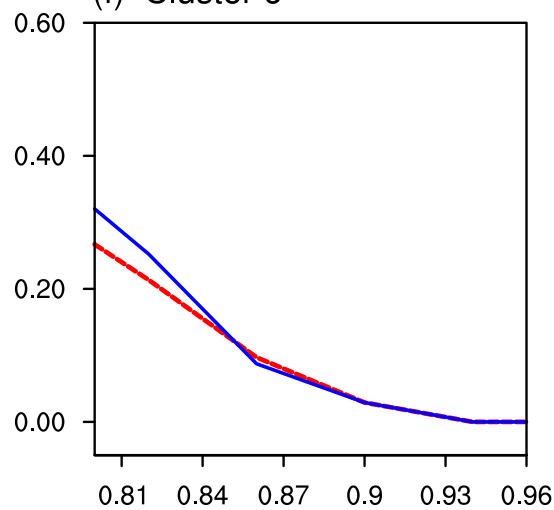

FIG. 11. Empirical PDFs (\%) of the OLMP and MLMP for the six identified clusters of precipitation extremes in the warm season. Blue solid lines and red dashed lines indicate the observation and the CCSM4 simulation, respectively. Only spatial correlation coefficients $>0.80$ are plotted.

their representations in the model tend to be resolution dependent and more problematic. Similar issues are also found for precipitation extremes over the Midwest and over the southwest mountainous region during the cool season.

Metrics for assessing a model's potential ability in representing precipitation extremes are subsequently designed by taking advantage of the cluster-specific LMPs. Defining the observed LMPs as a base function, spatial correlations between this base function and daily 500-hPa height anomalies are computed to obtain both observed and simulated daily LMP indices (OLMP vs MLMP). Comparison of the right tail of the MLMP PDF with that of the OLMP PDF for the same period reveals 
(a) Cluster 1

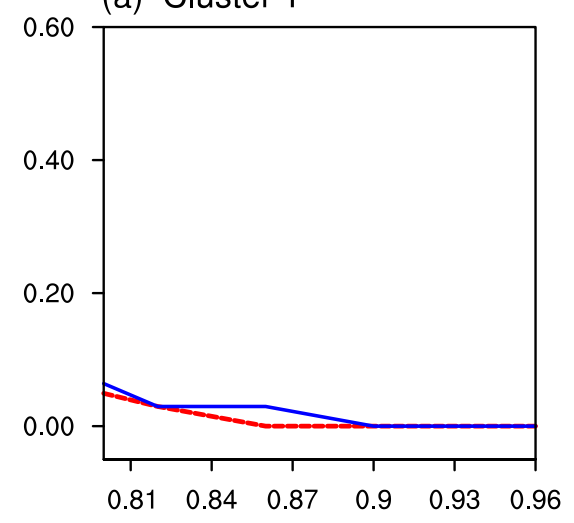

(c) Cluster 3

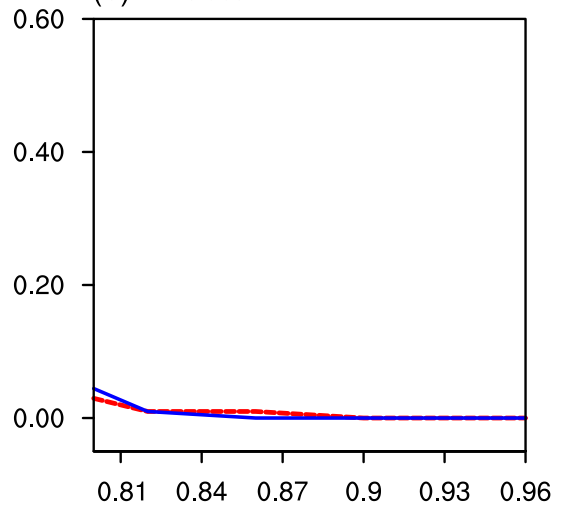

(b) Cluster 2

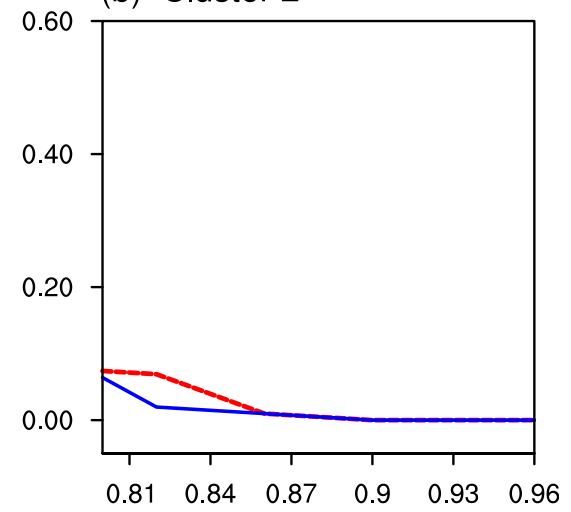

(d) Cluster 4

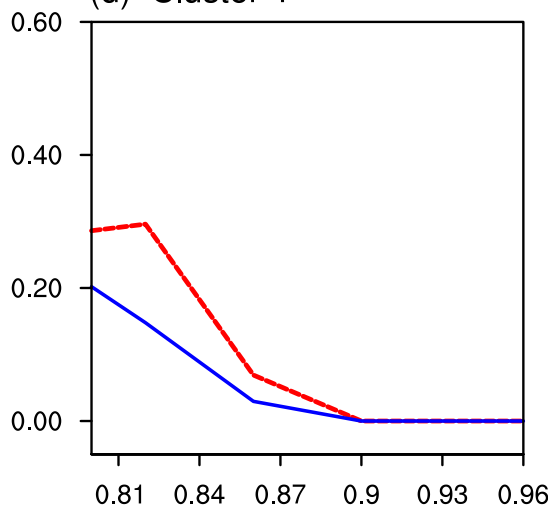

(e) Cluster 5

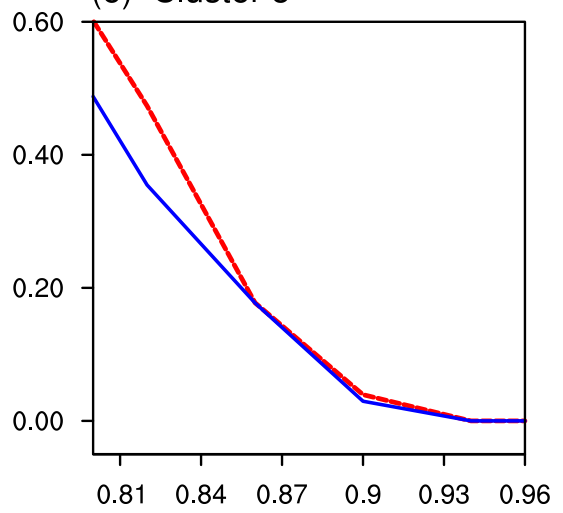

FIG. 12. As in Fig. 11, but for the cool season (and without cluster 6).

that a substantial model bias in the occurrence frequency of a canonical LMP is directly responsible for an analogous bias in the occurrence of the corresponding EPP. The discrepancies between the CCSM4's representation of LMPs and EPPs over the Midwest are also reflected by the MLMP-regressed EPP patterns. These results demonstrate the efficacy of LMP-based metrics in evaluating a model's potential for accurately representing the basic statistics (distribution and frequency) of extreme precipitation events. Ongoing and future work includes an examination of the dynamical origins of the LMPs identified here and their connections to major planetary-scale climate modes (PCMs) such as El Niño-Southern Oscillation (ENSO) and annular modes (AMs). The LMP-based metrics will also be applied to more CMIP5-participating models to further understand its value and limitations. Given that the model's historical simulation successfully reproduces observed behavior of EPPs over the United 
States, an additional plan is to investigate the potential changes of these EPPs under global warming scenarios using the model's future projections.

Acknowledgments. This study is supported by the DOE Office of Science Regional and Global Climate Modeling (RGCM) program through a cooperative agreement between the DOE and Georgia Institute of Technology under Contract DE-SC0012554. Yi Deng is also partly supported by the National Science Foundation Climate and Large-Scale Dynamics (CLD) program through Grants AGS-1147601, AGS-1354402, and AGS-1445956.

\section{REFERENCES}

Adams, D. K., and A. C. Comrie, 1997: The North American monsoon. Bull. Amer. Meteor. Soc., 78, 2197-2213, doi:10.1175/1520-0477(1997)078<2197:TNAM>2.0.CO;2.

Anderson, C. J., and R. W. Arritt, 2001: Mesoscale convective systems over the United States during the 1997-98 El Niño. Mon. Wea. Rev., 129, 2443-2457, doi:10.1175/ 1520-0493(2001)129<2443:MCSOTU>2.0.CO;2.

Asadieh, B., and N. Y. Krakauer, 2015: Global trends in extreme precipitation: Climate models versus observations. Hydrol. Earth Syst. Sci., 19, 877-891, doi:10.5194/hess-19-877-2015.

Berbery, E. H., 2001: Mesoscale moisture analysis of the North American monsoon. J. Climate, 14, 121-137, doi:10.1175/ 1520-0442(2001)013<0121:MMAOTN>2.0.CO;2.

Bowden, J. H., C. G. Nolte, and T. L. Otte, 2013: Simulating the impact of the large-scale circulation on the 2-m temperature and precipitation climatology. Climate Dyn., 40, 1903-1920, doi:10.1007/s00382-012-1440-y.

Bradbury, J. A., B. D. Keim, and C. P. Wake, 2003: The influence of regional storm tracking and teleconnections on winter precipitation in the northeastern United States. Ann. Assoc. Amer. Geogr., 93, 544-556, doi:10.1111/1467-8306.9303002.

Brommer, D. M., 2012: Reconsidering duration in assessing the character of precipitation. Geogr. Compass, 6, 385-400, doi:10.1111/j.1749-8198.2012.00494.x.

_ R. S. Cerveny, and R. C. Balling Jr., 2007: Characteristics of long-duration precipitation events across the United States. Geophys. Res. Lett., 34, L22712, doi:10.1029/2007GL031808.

Chang, E. K. M., S. Lee, and K. L. Swanson, 2002: Storm track dynamics. J. Climate, 15, 2163-2183, doi:10.1175/ 1520-0442(2002)015<02163:STD > 2.0.CO;2.

Changnon, S. A., D. Changnon, and T. R. Karl, 2006: Temporal and spatial characteristics of snowstorms in the contiguous United States. J. Appl. Meteor. Climatol., 45, 1141-1155, doi:10.1175/ JAM2395.1.

Chen, M.-Y., W. Shi, P. Xie, V. Silva, V. Kousky, R. Higgins, and J. Janowiak, 2008: Assessing objective techniques for gaugebased analyses of global daily precipitation. J. Geophys. Res., 113, D04110, doi:10.1029/2007JD009132.

Cook, K. H., G. A. Meehl, and J. M. Arblaster, 2012: Monsoon regimes and processes in CCSM4. Part II: African and American monsoon systems. J. Climate, 25, 2609-2621, doi:10.1175/JCLI-D-11-00185.1.

DeFlorio, M. J., D. W. Pierce, D. Cayan, and A. Miller, 2013: Western U.S. extreme precipitation events and their relation to ENSO and PDO in CCSM4. J. Climate, 26, 4231-4243, doi:10.1175/JCLI-D-12-00257.1.

Deng, Y., and T. Jiang, 2011: Intraseasonal modulation of the North Pacific storm track by tropical convection in boreal winter. J. Climate, 24, 1122-1137, doi:10.1175/2010JCLI3676.1.

Easterling, D. R., G. A. Meehl, C. Parmesan, S. Changnon, T. Karl, and L. Mearns, 2000: Climate extremes: Observations, modeling, and impacts. Science, 289, 2068-2074, doi:10.1126/ science.289.5487.2068.

Feldstein, S. B., and U. Dayan, 2008: Circumglobal teleconnections and wave packets associated with Israeli winter precipitation. Quart. J. Roy. Meteor. Soc., 134, 455-467, doi:10.1002/qj.225.

Fritsch, J. M., R. J. Kane, and C. R. Chelius, 1986: The contribution of mesoscale convective weather systems to the warmseason precipitation in the United States. J. Climate Appl. Meteor., 25, 1333-1345, doi:10.1175/1520-0450(1986)025<1333: TCOMCW $>2.0 . \mathrm{CO} ; 2$.

Gent, P. R., and Coauthors, 2011: The Community Climate System Model version 4. J. Climate, 24, 4973-4991, doi:10.1175/ 2011JCLI4083.1.

Gong, X.-F., and M. B. Richman, 1995: On the application of cluster analysis to growing season precipitation data in North America east of the Rockies. J. Climate, 8, 897-931, doi:10.1175/1520-0442(1995)008<0897:OTAOCA > 2.0.CO;2.

Groisman, P. Ya., and Coauthors, 1999: Changes in the probability of heavy precipitation: Important indicators of climatic change. Climatic Change, 42, 243-283, doi:10.1023/ A:1005432803188.

—, R. W. Knight, D. Easterling, T. Karl, G. Hegerl, and V. Razuvaev, 2005: Trends in intense precipitation in the climate record. J. Climate, 18, 1326-1350, doi:10.1175/ JCLI3339.1.

Hennessy, K. J., J. M. Gregory, and J. F. B. Mitchell, 1997: Changes in daily precipitation under enhanced greenhouse conditions. Climate Dyn., 13, 667-680, doi:10.1007/s003820050189.

Higgins, R. W., Y. Yao, E. Yarosh, J. Janowiak, and K. Mo, 1997: Influence of the Great Plains low-level jet on summertime precipitation and moisture transport over the central United States. J. Climate, 10, 481-507, doi:10.1175/ 1520-0442(1997)010<0481:IOTGPL > 2.0.CO;2.

Hilgendorf, E. R., and R. H. Johnson, 1998: A study of the evolution of mesoscale convective systems using WSR88D data. Wea. Forecasting, 13, 437-452, doi:10.1175/ 1520-0434(1998)013<0437:ASOTEO>2.0.CO;2.

Holman, K. D., D. J. Lorenz, and M. Notaro, 2014: Influence of the background state on Rossby wave propagation into the Great Lakes region based on observations and model simulations. J. Climate, 27, 9302-9322, doi:10.1175/JCLI-D-13-00758.1.

Iorio, J. P., P. B. Duffy, B. Govindasamy, S. Thompson, M. Khairoutdinov, and D. Randall, 2004: Effects of model resolution and subgrid-scale physics on the simulation of precipitation in the continental United States. Climate Dyn., 23, 243-258, doi:10.1007/s00382-004-0440-y.

Jiang, T., and Y. Deng, 2011: Downstream modulation of North Pacific atmospheric river activity by East Asian cold surges. Geophys. Res. Lett., 38, L20807, doi:10.1029/2011GL049462.

_ K. J. Evans, Y. Deng, and X. Dong, 2014: Intermediate frequency atmospheric disturbances: A dynamical bridge connecting western U.S. extreme precipitation with East Asian cold surges. J. Geophys. Res. Atmos., 119, 3723-3735, doi:10.1002/2013JD021209.

Kalkstein, L. S., G.-R. Tan, and J. A. Skindlov, 1987: An evaluation of three clustering procedures for use in synoptic climatological 
classification. J. Climate Appl. Meteor., 26, 717-730, doi:10.1175/ 1520-0450(1987)026<0717:AEOTCP >2.0.CO;2.

Kalnay, E., and Coauthors, 1996: The NCEP/NCAR 40-Year Reanalysis Project. Bull. Amer. Meteor. Soc., 77, 437-471, doi:10.1175/1520-0477(1996)077<0437:TNYRP>2.0.CO;2.

Karl, T. R., and R. W. Knight, 1998: Secular trends of precipitation amount, frequency, and intensity in the United States. Bull. Amer. Meteor. Soc., 79, 231-241, doi:10.1175/1520-0477(1998)079<0231: STOPAF $>2.0 . \mathrm{CO} ; 2$.

Kitabatake, N., 2002: Extratropical transformation of Typhoon Vicki (9807): Structural change and the role of uppertropospheric disturbances. J. Meteor. Soc. Japan, 80, 229 247, doi:10.2151/jmsj.80.229.

Kunkel, K. E., D. R. Easterling, K. Redmond, and K. Hubbard, 2003: Temporal variations of extreme precipitation events in the United States: 1895-2000. Geophys. Res. Lett., 30, 1900, doi:10.1029/2003GL018052.

D. Kristovich, B. Gleason, L. Stoecker, and R. Smith, 2010: Recent increases in U.S. heavy precipitation associated with tropical cyclones. Geophys. Res. Lett., 37, L24706, doi:10.1029/2010GL045164.

_ - and Coauthors, 2013: Monitoring and understanding trends in extreme storms: State of knowledge. Bull. Amer. Meteor. Soc., 94, 499-514, doi:10.1175/BAMS-D-11-00262.1.

Lau, K.-M., and H.-Y. Weng, 2002: Recurrent teleconnection patterns linking summertime precipitation variability over East Asia and North America. J. Meteor. Soc. Japan, 80, 13091324, doi:10.2151/jmsj.80.1309.

Leung, L. R., and Y. Qian, 2003: The sensitivity of precipitation and snowpack simulations to model resolution via nesting in regions of complex terrain. J. Hydrometeor., 4, 1025-1043, doi:10.1175/1525-7541(2003)004<1025:TSOPAS > 2.0.CO;2.

Luterbacher, J., M. A. Liniger, A. Menzel, N. Estrella, P. DellaMarta, C. Pfister, T. Rutishauser, and E. Xoplaki, 2007: Exceptional European warmth of autumn 2006 and winter 2007: Historical context, the underlying dynamics, and its phenological impacts. Geophys. Res. Lett., 34, L12704, doi:10.1029/ 2007 GL029951.

Marshall, S., J. O. Roads, and R. J. Oglesb, 1997: Effects of resolution and physics on precipitation in the NCAR Community Climate Model. J. Geophys. Res., 102, 19529-19541, doi:10.1029/97JD01428.

Martin, J. E., 1998: The structure and evolution of a continental winter cyclone. Part I: Frontal structure and the occlusion process. Mon. Wea. Rev., 126, 303-328, doi:10.1175/1520-0493(1998)126<0303: TSAEOA $>2.0 . \mathrm{CO} ; 2$.

_ J. D. Locatelli, P. Hobbs, P. Wang, and J. Castle, 1995: Structure and evolution of winter cyclones in the central United States and their effects on the distribution of precipitation. Part I: A synoptic-scale rainband associated with a dryline and lee trough. Mon. Wea. Rev., 123, 241-264, doi:10.1175/1520-0493(1995)123<0241:SAEOWC >2.0.CO;2.

Meehl, G. A., J. M. Arblaster, and C. Tebaldi, 2005: Understanding future patterns of precipitation intensity in climate model simulations. Geophys. Res. Lett., 32, L18719, doi:10.1029/ 2005GL023680.

Mo, K. C., 2000: Intraseasonal modulation of summer precipitation over North America. Mon. Wea. Rev., 128, 1490-1505, doi:10.1175/ 1520-0493(2000)128<1490:IMOSPO > 2.0.CO;2.

, J. N. Paegle, and R. W. Higgins, 1997: Atmospheric processes associated with summer floods and droughts in the central United States. J. Climate, 10, 3028-3046, doi:10.1175/ 1520-0442(1997)010<3028:APAWSF>2.0.CO;2.
Myoung, B., and Y. Deng, 2009: Interannual variability of the cyclonic activity along the U.S. Pacific coast: Influences on the characteristics of winter precipitation in the western United States. J. Climate, 22, 5732-5747, doi:10.1175/ 2009JCLI2889.1.

Park, T.-W., C.-H. Ho, and Y. Deng, 2014: A synoptic and dynamical characterization of wave-train and blocking cold surge over East Asia. Climate Dyn., 43, 753-770, doi:10.1007/ s00382-013-1817-6.

Rauber, R. M., J. E. Walsh, and D. J. Charlevoix, 2005: Severe and Hazardous Weather: An Introduction to High-Impact Meteorology. 2nd ed. Kendall Hunt Publishing Company, 161 pp.

Rojas, M., 2006: Multiply nested regional climate simulation for southern South America: Sensitivity to model resolution. Mon. Wea. Rev., 134, 2208-2223, doi:10.1175/ MWR3167.1.

Rudari, R., D. Entekhabi, and G. Roth, 2005: Large-scale atmospheric patterns associated with mesoscale features leading to extreme precipitation events in northwestern Italy. $A d v . W a-$ ter Resour., 28, 601-614, doi:10.1016/j.advwatres.2004.10.017.

Ryoo, J.-M., Y. Kaspi, D. Waugh, G. Kiladis, D. Waliser, E. Fetzer, and J. Kim, 2013: Impact of Rossby wave breaking on U.S. West Coast winter precipitation during ENSO events. J. Climate, 26, 6360-6382, doi:10.1175/JCLI-D-12-00297.1.

Schubert, S. D., Y. Chang, M. Suarez, and P. Pegion, 2008: ENSO and wintertime extreme precipitation events over the contiguous United States. J. Climate, 21, 22-39, doi:10.1175/ 2007JCLI1705.1.

Sheffield, J., and Coauthors, 2013a: North American climate in CMIP5 experiments. Part I: Evaluation of historical simulations of continental and regional climatology. J. Climate, 26, 9209-9245, doi:10.1175/JCLI-D-12-00592.1.

— , and Coauthors, 2013b: North American climate in CMIP5 experiments. Part II: Evaluation of historical simulations of intraseasonal to decadal variability. J. Climate, 26, 9247-9290, doi:10.1175/JCLI-D-12-00593.1.

Sperber, K. R., S. Hameed, G. Potter, and J. Boyle, 1994: Simulation of the northern summer monsoon in the ECMWF model: Sensitivity to horizontal resolution. Mon. Wea. Rev., 122, 2461-2481, doi:10.1175/1520-0493(1994)122<2461: SOTNSM $>2.0 . \mathrm{CO} ; 2$.

Takaya, K., and H. Nakamura, 2001: A formulation of a phase-independent wave-activity flux for stationary and migratory quasigeostrophic eddies on a zonally varying basic flow. J. Atmos. Sci., 58, 608-627, doi:10.1175/ 1520-0469(2001)058<0608:AFOAPI > 2.0.CO;2.

Tomozeiu, R., S. Stefan, and A. Busuioc, 2005: Winter precipitation variability and large-scale circulation patterns in Romania. Theor. Appl. Climatol., 81, 193-201, doi:10.1007/ s00704-004-0082-3.

Wang, B., and LinHo, 2002: Rainy season of the Asian-Pacific summer monsoon. J. Climate, 15, 386-398, doi:10.1175/ 1520-0442(2002)015<0386:RSOTAP $>2.0 . C O ; 2$.

Wang, S., L. Hipps, R. Gillies, X. Jiang, and A. Moller, 2010: Circumglobal teleconnection and early summer rainfall in the US intermountain west. Theor. Appl. Climatol., 102, 245-252, doi:10.1007/s00704-010-0260-4.

Ward, J. H., 1963: Hierarchical grouping to optimize an objective function. J. Amer. Stat. Assoc., 58, 236-244, doi:10.1080/ 01621459.1963.10500845.

Wehner, M. F., 2013: Very extreme seasonal precipitation in the NARCCAP ensemble: Model performance and projections. Climate Dyn., 40, 59-80, doi:10.1007/s00382-012-1393-1. 
_ R. Smith, G. Bala, and P. Duffy, 2010: The effect of horizontal resolution on simulation of very extreme US precipitation events in a global atmosphere model. Climate Dyn., 34, 241247, doi:10.1007/s00382-009-0656-y.

Zhao, S.-Y., and S. Yang, 2014: Dynamical prediction of the early season rainfall over southern China by the NCEP Climate Forecast System. Wea. Forecasting, 29, 1391-1401, doi:10.1175/WAF-D-14-00012.1.

, —_ , Y. Deng, and Q.-P. Li, 2015: Skills of yearly prediction of the early-season rainfall over southern China by the NCEP
Climate Forecast System. Theor. Appl. Climatol., 122, 743754, doi:10.1007/s00704-014-1333-6.

_- Y. Deng, and R. X. Black, 2016: Warm season dry spells in the central and eastern United States: Diverging skill in climate model representation. J. Climate, 29, 5617-5624, doi:10.1175/ JCLI-D-16-0321.1.

Zolina, O., A. Kapala, C. Simmer, and S. K. Gulev, 2004: Analysis of extreme precipitation over Europe from different reanalyses: A comparative assessment. Global Planet. Change, 44, 129-161, doi:10.1016/j.gloplacha.2004.06.009. 